\title{
Advancing the iid Test Based on Integration across the Correlation Integral: Ranges, Competition and Power
}

Evžen Kočenda

Luboš Briatka

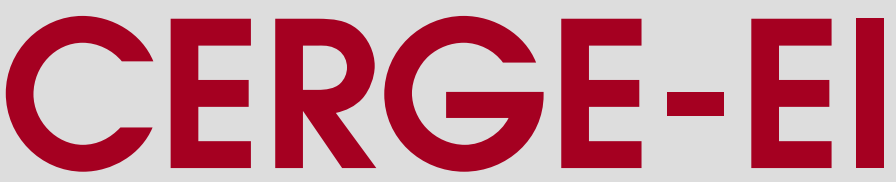

Charles University Center for Economic Research and Graduate Education Academy of Sciences of the Czech Republic Economics Institute 
Advancing the iid Test Based on Integration across the Correlation Integral:

Ranges, Competition, and Power

Evžen Kočenda ${ }^{a}$ and L'uboš Briatka ${ }^{b}$

\begin{abstract}
This paper builds on Kočenda (2001) and extends it in two ways. First, two new intervals of the proximity parameter $\varepsilon$ (over which the correlation integral is calculated) are specified. For these $\varepsilon$-ranges new critical values for various lengths of the data sets are introduced and through Monte Carlo studies it is shown that within new $\varepsilon$-ranges the test is even more powerful than within the original $\varepsilon$ range. A sensitivity analysis of the critical values with respect to $\varepsilon$-range choice is also given. Second, a comparison with existing results of the controlled competition of Barnett et al. (1997) as well as broad power tests on various nonlinear and chaotic data are provided. The results of the comparison strongly favor our robust procedure and confirm the ability of the test in finding nonlinear dependencies. An empirical comparison of the new $\varepsilon$-ranges with the original one shows that the test within the new $\varepsilon$-ranges is able to detect hidden patterns with much higher precision. Finally, new user-friendly and fast software is introduced.
\end{abstract}

Tento článek je rozšířením studie Kočendy (2001) v nasledujících dvou rovinách. Za prvé, v článku jsou specifikovány dva nové intervaly pro proximity parametr $\varepsilon$, přes které se počítá korelační integrál. Pro tyto intervaly jsou tabulovány nové kritické hodnoty a pomocí Monte Carlo studie se ukazuje, že test je citlivější než při použití původního intervalu. Rovněž je provedena analýza citlivosti těchto kritických hodnot na změnu intervalu proximity parametru $\varepsilon$. Za druhé, srovnáním výsledků porovnání testů, kterou provedl Barnett et al. (1997), a výpočtem síly testu pro rozličná nelineární a chaotická data pro všechny intervaly poukazujeme na silnou schopnost testu odhalovat nelineární závislosti v datech. Empirické porovnání s původními výsledky ukázalo, že test je s použitím nových intervalů schopen zachytit skryté struktury $\mathrm{v}$ datech $\mathrm{s}$ ještě větší citlivostí. Na závěr, přinášíme nový, uživatelsky př́ijemný a rychlý software pro výpočet testovací statistiky.

Keywords: chaos, nonlinear dynamics, correlation integral, Monte Carlo, singleblind competition, power tests, high-frequency economic and financial data

JEL Classification: C14, C15, C52, C87, F31, G12.

a CERGE-EI, Prague; CEPR, London; William Davidson Institute at University of Michigan Business School

b CERGE-EI, Prague

We would like to thank William Barnett, Jan Hanousek, Blake LeBaron, Elzevio Ronchetti, Jan Ámos Víšek, Petr Zemčík, and participants of the Czech Econometric Society Workshop (2003) for helpful comments. We also thank Marian Baranec, Ivo Burger, and Petr Sklenár for their computing assistance that helped to considerably shorten the time needed to perform simulations in this paper. The usual disclaimer applies. 


\section{Introduction}

Growing interest as well as practical needs of researchers in testing for nonlinearity and chaos in high-frequency economic and financial data has prompted the design of various methods to accomplish the task. Among them, a well known BDS test was devised by Brock, Dechert, Scheinkman and LeBaron (1996) as a non-parametric method of testing for nonlinear patterns in time series. ${ }^{1}$ The method is based on the correlation integral described by Grassberger and Procaccia (1983) and is unique in its ability to detect nonlinearities independent of linear dependencies in the data. The null hypothesis is that data in a time series are independently and identically distributed (iid); an alternative is not specified. In order to conduct the BDS test, two free variables (embedding dimension $m$ and proximity parameter $\varepsilon$ ) must be chosen ex ante, with limited guidance from statistical theory; thus it is likely that inappropriate values may be chosen. Kočenda (2001) has suggested an alternative test which, through integrating across the correlation integral, avoids arbitrary selection of the proximity parameter $\varepsilon$ and allows for running the test across an empirically endorsed set of embedding dimensions $m$.

This paper builds on Kočenda (2001) and increases the operational ability of the alternative test in three ways. We improve the choice of the interval of the proximity parameter $\varepsilon$ over which the correlation integral is calculated and suggest the range that maximizes the power of the test. We also bring necessary sets of critical values for various lengths of data and provide an analysis of their sensitivity with respect to the choice of proximity parameter range. Further, we compare the test with existing results of the single-blind controlled competition of Barnett et al. (1997) and perform power tests on various chaotic (nonlinear) and noisy chaotic data. The results strongly attest to our robust procedure. Additionally, new compact software to run the test, as well as allowing for associated simulations, is introduced as freeware.

Section 2 provides a brief theoretical background and describes the motivation for $\varepsilon$-range choice in greater detail. Section 3 deals with the choice of 
$\varepsilon$-range and supplies critical values generated by the Monte Carlo technique. Section 4 contains a sensitivity analysis of critical values over different ranges of proximity parameter $\varepsilon$. Section 5 examines power tests, Section 6 describes the new software, and Section 7 briefly concludes.

\section{Theoretical Background and Motivation}

Chaotic systems of low dimensionality can generate seemingly random numbers that may give an impression of white noise, thereby hiding their true nature. Under presumed randomness, a nonlinear pattern can hide without being detected. Exchange rates, stock market returns and other macroeconomic variables of generally high frequency, for example, may originate from low-dimensional chaos. Detection of nonlinear hidden patterns in such time series provides important information about their behavior and improves forecasting ability over short time periods. ${ }^{2}$

The analysis of chaotic systems often starts with computing a correlation dimension because of the ease of computation and the availability of sampling theory. The aforementioned BDS test is based on such a technique and was designed to detect hidden patterns in stochastic time series. This test is a nonparametric test of the null hypothesis that the data are independently and identically distributed (iid) against an unspecified alternative. The procedure has power against both deterministic and stochastic systems. The BDS test is a wellknown standard procedure; it is widely used for its ability to deal with stochastic time series, which makes its application in modern macroeconomics and financial economics extremely appealing.

While the BDS statistic is easy to compute, it suffers from an obvious drawback - the values of two parameters, proximity parameter $\varepsilon$ (also referred to as tolerance distance or metric bound) and embedding dimension $m$, must be

\footnotetext{
${ }^{1}$ We cite other well known tests later in Section 5.1.

${ }^{2}$ Recent advances in research of chaos allow researchers to control chaotically behaving systems in various fields of physics, biology, chemistry, and medicine. Effective control for chaos in economics does not seem to be more realistic than discovering Shangri-la, though.
} 
determined ex ante. ${ }^{3}$ Further, the BDS statistic, when used for testing, has often been evaluated for only few values of the proximity parameter $\varepsilon$. This was brought about, in part, by the Monte Carlo studies of Hsieh and LeBaron (1988) who tested the asymptotic normality of the statistic for three values of the parameter, and tabulated the corresponding critical values.

The alternative test of Kočenda (2001) suggests considering an OLSestimate of the correlation dimension over a range of $\varepsilon$-values, and is thus closer in spirit to the original correlation dimension than is the BDS test (for full details see the original paper). ${ }^{4}$ The test rests upon the concept of the correlation integral, developed by Grassberger and Procaccia (1983). Formally, let $\left\{x_{t}\right\}$ be a scalar time series generated randomly according to a density function $f$. Form $m$ dimensional vectors, called $m$-histories, $x_{t}^{m}=\left(x_{t}, x_{t+1}, \ldots, x_{t+m-1}\right)$. The correlation integral at embedding dimension $m$ is computed as

$$
C_{m, T}(\varepsilon)=2 \sum_{t=1}^{T_{m-1}} \sum_{s=t+1}^{T_{m}} I_{\varepsilon}\left(x_{t}^{m}, x_{s}^{m}\right) /\left(T_{m}\left(T_{m}-1\right)\right),
$$

where $T_{m}=T-m+1$, and $I_{\varepsilon}\left(x_{t}^{m}, x_{s}^{m}\right)$ is an indicator function of the event

$$
\left\|x_{t}^{m}-x_{s}^{m}\right\|=\max _{i=0,1, \ldots m-1}\left|x_{t+i}-x_{s+i}\right|<\varepsilon .
$$

Thus, the correlation integral measures the fraction of pairs that lie within the tolerance distance $\varepsilon$ for the particular embedding dimension $m$.

The alternative statistic uses a number of tolerance distances chosen from a specific range for each particular embedding dimension by calculating the slope of the log of the correlation integral versus the log of the proximity parameter over a broad range of values of the proximity parameter. The slope coefficients, $\beta_{m}$, can be estimated as

$$
\beta_{m}=\frac{\sum_{\varepsilon}(\ln (\varepsilon)-\overline{\ln (\varepsilon)}) \cdot\left(\ln \left(C_{m, T}(\varepsilon)\right)-\overline{\ln \left(C_{m, T}(\varepsilon)\right)}\right)}{\sum_{\varepsilon}(\ln (\varepsilon)-\overline{\ln (\varepsilon)})^{2}},
$$

\footnotetext{
${ }^{3}$ Some guidance can be found for example in Dechert (1994), Brock, Dechert, Scheinkman and LeBaron (1996), de Lima (1992), and Hsieh and LeBaron (1988).

${ }^{4}$ It is worthwhile noting that originally an important reason to develop the BDS test was that point
} 
which equals to calculating the slope coefficient $\beta_{m}$ from the least squares regression

$$
\ln \left(C_{m, T}\left(\varepsilon_{i}\right)\right)=\alpha_{m}+\beta_{m} \ln \left(\varepsilon_{i}\right)+u_{i} ; \quad i=1, \ldots, n
$$

where $\ln (\varepsilon)$ is the $\log$ of proximity parameter (tolerance distance), $\ln \left(C_{m, T}(\varepsilon)\right)$ is the correlation integral value, $m$ is the embedding dimension, and the variables with a bar denote the mean of their counterparts without a bar. ${ }^{5}$ Since a range of different tolerance distances $\varepsilon$ is used the slope coefficients $\beta_{m}$ do not depend on an arbitrary choice of $\varepsilon$. As for the choice of embedding dimension $m$, a range of empirically endorsed dimensions $m$ is used, which gives enough variety to capture a more complex dimensional structure without eliminating unexplored opportunities. One theoretical feature of the slope coefficients $\beta_{m}$ is that under the null hypothesis that the data are iid, these slopes should equal the respective embedding dimension $m$ at which the statistic is calculated (i.e. $\left.\beta_{m}=m\right)^{6}$ However, slope coefficient estimates $\beta_{m}$ are smaller than respective embedding dimension $m$, i.e. $\beta_{m} \leq m$. For details and proof see the appendix.

\section{Proximity parameter range and critical values}

Kočenda (2001) performed a Monte Carlo study with 10,000 replications of the distribution of the $\beta_{m}$ statistic under the null hypothesis of iid data. ${ }^{7}$ Critical values were tabulated for data-length of 500, 1000, and 2500 observations allowing for nine embedding dimensions $m(2-10)$. The range of proximity parameter $\varepsilon$, for which the critical values were generated, extends over the specific interval: $n=41$ proximity parameters $\varepsilon$ ranging over the interval $(0.25 \sigma, 1.00 \sigma)$ in proportionally equal increments ( $\sigma$ being standard deviation of a sample).

The above original interval is chosen sensibly to allow for hidden patterns

estimates of the correlation dimension were very unstable across values of $\varepsilon$.

${ }^{5}$ As $\beta_{m}$ is, in fact, an OLS estimate of the slope coefficient, by econometric tradition it should be labeled as $\hat{\beta}_{m}$. For the sake of notational simplicity, we decided to omit the hat.

${ }^{6}$ See Hsieh (1991).

${ }^{7}$ A compound random number generator based on the idea of Collings (1987) and constructed from 17 generators described by Fishman and Moore (1982) was employed to generate iid data. 
corresponding to very narrow tolerance distances. However, a single $\varepsilon$-range prevents observing whether and how sensitive the tabulated critical values are to a choice of different $\varepsilon$-range. Further, the originally chosen $\varepsilon$-range does not need to be an optimal range; e.g. the range that, when used, maximizes the power of the test. We elaborate on this issue in the following sections.

\subsection{Range selection}

The issue of the $\varepsilon$-range choice is complicated by the fact that we cannot theoretically derive a correct range of proximity parameters. This is due to the fact that the behavior of the $\beta_{m}$ statistic within an $\varepsilon$-range is closely related to the composition of the analyzed data. Therefore it is possible that one $\varepsilon$-range is more appropriate for some kind of data and a different e-range for another one. (We will come back to these issues in Section 5.4) For this reason, we select two additional ranges of proximity parameters to study whether and how the critical values behave. ${ }^{8}$ We proceed with calculating critical values, then compare them for three different intervals, and finally perform a series of power tests to expose the range that provides the test with the greatest power against the null hypothesis. Such a range should be considered the optimal one. Since both the BDS and the Kočenda tests start with computing the correlation integral, we use the BDS literature as a point of reference on what proximity parameters are often used as required entries to compute the test. Table 1 offers a summary of selected representative literature dealing with the issue.

To repeat, Kočenda (2001) provides critical values for proximity parameter in a range of $(0.25 \sigma, 1.00 \sigma)$; this is our first (original) interval. This range is the most discriminating range of the proximity parameters $\varepsilon$, which means that it takes into account primarily very small tolerance distances among the data in a sample. By this token the test is able to uncover only a specific class of non-

\footnotetext{
${ }^{8}$ The issue of different $\mathcal{E}$-ranges is discussed also in Belaire-Franch (2003) who argues that although the power of Kočenda's test can be more powerful than the BDS test, more than one $\mathcal{E}$ range should be used. The two additional ranges used in his study were constructed only as an additive extension to the original range without any theoretical or empirical argument given to support the choice.
} 
iid patterns within data.

The second interval is motivated by the results of Monte Carlo studies performed by Hsieh and LeBaron (1988), who found that the power and size of the BDS test is maximized when proximity parameter $\varepsilon$ is chosen between 0.5 and 1.5 of the standard deviation of the sample. For this reason we have chosen to calculate values of correlation integral for $(0.50 \sigma, 1.50 \sigma)$ range of proximity parameters. Table 1 illustrates that, indeed, numerous empirical studies used isolated values of proximity parameter within such a range of values.

The third interval represents the broadest range of sensible proximity parameter values that are used in the empirical literature. Since we concur with Kanzler (1999), who shows that the asymptotic normality of the BDS test depends on the correct choice of proximity parameter, we employ the broad interval of proximity parameters within $(0.25 \sigma, 2.00 \sigma)$ in order to avoid omitting its possible correct values when computing the statistic of the Kočenda test. The ample use of proximity parameter values from within the third range is again documented in Table 1.

\subsection{Critical values}

In order to derive statistical properties of the Kočenda test when different proximity parameter ranges are used, a Monte Carlo study of the distribution of the statistic under the null hypothesis is performed. ${ }^{9}$ Our sample consists of drawing 20,000 time series from a standard normal distribution of length 500, 1000, and 2500 observations in each series.

The data were generated using an inversive congruential generator. The first 1000 observations were discarded to avoid dependency on the initial condition. Finally, the generated data were randomly shuffled to reduce any hidden nonrandom dependencies in the data. The practical advantage of an inversive congruential generator (ICG) against a linear congruential generator (LCG) is that ICG guarantees the absence of a lattice structure. We have opted for the ICG for its superiority, despite the fact that it is significantly slower than LCG. Both generators

\footnotetext{
${ }^{9}$ Monte Carlo simulations are used instead of distribution theory because the test is non-parametric.
} 
are easy to implement and there is abundant literature available with the portable code, parameters and test results. ${ }^{10}$ For a concise survey of the performance of inversive random number generators in theoretical and empirical tests, as well as tables of parameters to implement inversive generators see Hellekalek (1995). For a survey of the latest concepts and results of random number generation, we recommend starting with L'Ecuyer (2004).

Following Kočenda (2001), the generated iid samples were exposed to the computational procedure of the correlation integral allowing for nine embedding dimensions $m$ (2-10) and 41 tolerance distances $\varepsilon$ ranging over the three different intervals introduced in section 3.1, in proportionally equal increments. Then, slope coefficient estimates of $\beta_{m}$ were calculated according to equation (2.3a). When computing the slope coefficient estimates of $\beta_{m}$, a cut-off point was set to eliminate the erratic portion of the trajectories at the highest embedding dimensions, $m$ (7-10). Such a cut-off point does not affect the analysis for lower embedding dimensions $m$, but considerably reduces the increasing variance as embedding dimension $m$ grows larger and tolerance distance $\varepsilon$ becomes smaller. The cut-off point represents the number of matches that maximizes the power of the test or, implicitly, minimizes error of the second kind. ${ }^{11}$

Finally, quantiles for the slope coefficient estimates $\beta_{m}$ at different dimensional levels were tabulated. Table 2 presents the quantiles to allow a hypothesis testing at levels of $1 \%, 2 \%, 5 \%$, and $10 \%$ for time series of 500 observations. Tables 3 and 4 present the quantiles for time series of the length 1000 and 2500 observations, respectively. Let $L_{\alpha}$ and $U_{\alpha}$ be lower and upper

\footnotetext{
${ }^{10}$ The described data-generating strategy was chosen for two reasons. First, an ICG effectively eliminates repetitiveness in the data caused by the limitations of computer hardware. Secondly, other methods such as hypothetically obtaining white noise residuals by estimating a generating process (i.e. AR, ARCH, GARCH, etc.) may possess some unaccounted for structural form which would bias the critical values in a Monte Carlo simulation. The issues of how the asymptotic distribution of the test statistics might be affected by the estimation process is discussed by de Lima (1998).

${ }^{11}$ By simulation it was found that such a number lies in the interval between 40 to 50 . To be on the safe side, the value of the correlation integral was constrained to be 50 . The "cut-off" value for $C_{m}(\varepsilon)$ must be chosen before slope coefficient estimates are computed. $C_{m}(\varepsilon)=50$ resulted from simulations that were compared with various trajectories resulting from the analysis conducted on different time series.
} 
bounds of the $(100-\alpha)$ percentage confidence interval. If $\left[\left(x<L_{\alpha}\right) \vee\left(x>U_{\alpha}\right)\right]$, then the null hypothesis of iid can be rejected at the $\alpha$ percent confidence level.

\section{Sensitivity of critical values to an $\varepsilon$-range choice}

When compared, critical values for equal length of a data sample and embedding dimension differ. Figure 1 summarizes how the critical values of the statistic vary with the choice of proximity parameter range. For each size of a data sample (500; $1000 ; 2500$ observations) we present dispersions of critical values at $2.5 \%$ and $97.5 \%$ quantiles. Dispersions, or relative changes of critical values, are calculated as respective quantile differences between critical values obtained for two specified intervals over particular embedding dimension. The relative changes are of various signs but in the figure they are pictured in absolute value for better accessibility.

Overall, the largest relative differences of critical values exist between pairs of ranges $[(0.25 \sigma, 1.00 \sigma)$ and $(0.50 \sigma, 1.50 \sigma)]$, and $[(0.25 \sigma, 1.00 \sigma)$ and $(0.25 \sigma$, $2.00 \sigma)]$. The differences in critical values between these two pairs range from $4 \%$ to $10 \%$ at embedding dimensions up to 5 and differences reach higher values as embedding dimension increases. This is a notable feature for $97.5 \%$ quantile where differences range from $10 \%$ to about $40 \%$; the increase in differences is correlated with embedding dimension and is inversely related to sample size.

The smallest differences, on other hand, exist between a pair of tabulated critical values of the newly suggested ranges $[(0.50 \sigma, 1.50 \sigma)$ and $(0.25 \sigma, 2.00 \sigma)]$. Specifically, all differences were below $8 \%$ or even smaller, below $3 \%$, at embedding dimensions from 1 to 5 . When we consider the values themselves, the differences are negligible.

Variation of critical values is not only associated with the range of proximity parameter but also with the value of embedding dimension used and with the size of a sample, as we already mentioned. To complete the assessment of differences among critical values tabulated for different ranges of proximity parameter, we provide Table 5, which contains absolute differences among critical values between pairs of all three $\varepsilon$-ranges. 
We have found that, in the case of a sample size of 2500 observations, the differences of critical values tend to increase with embedding dimension $m$ for all three pairs of $\varepsilon$-ranges (while this tendency can be traced for $97.5 \%$ quantile, it becomes less pronounced for $2.5 \%$ quantile). We can trace the same tendency for some pairs of $\varepsilon$-ranges in a sample size of 1000 observations. ${ }^{12}$ For a sample size of 500 observations the differences in critical values follow an erratic pattern. In general, the differences are also somewhat larger for a small sample size (e.g. in our case a sample of 500 observations is a small sample when compared to a sample size of 1000 or 2500 observations). The main reason is that as embedding dimension $m$ increases, fewer and fewer non-overlapping $m$-histories become available to compute the correlation integral. In a small sample, there are few data available and deviation of critical values is thus greater for the small data size. ${ }^{13}$

A further implication is that for samples of moderate size only a lowdimensional chaos is characterized. This is due to the fact that the estimates of $C_{1, T}$ show a far larger deviation around their asymptotic values when the samples are small than when they are large (Kanzler 1999). However, as we stated earlier, the correct choice of $\varepsilon$ is unknown. Moreover, small $\varepsilon$ causes the expected number of close histories to be small and thus renders estimation of $C_{m, T}$ less reliable. This means that the choice of $\varepsilon$ has a greater impact on the reliability of $C_{m, T}$ than on $C_{1, T}$.

The main result of sensitivity analysis of critical values is that they differ for three $\varepsilon$-ranges and these differences are smallest between the critical values of the ranges $[(0.50 \sigma, 1.50 \sigma)$ and $(0.25 \sigma, 2.00 \sigma)]$.

It may seem that when several intervals of proximity parameter $\varepsilon$ are proposed a problem of arbitrary selection of proximity parameter (in the BDS test) is transformed into the problem of selecting its appropriate range (in the Kočenda test). Fortunately, in the following section, we show that this is not the case.

\footnotetext{
${ }^{12}$ This is in line with the findings of Brock, Hsieh, and LeBaron (1993) and Kanzler (1999) with respect to the BDS test: As the embedding dimension $m$ increases, the BDS distribution moves away from its asymptotic distribution, the standard normal. The lower the dimension, the better the small-sample properties, whatever the sample size and size of the epsilon.
} 


\section{Performance and power of the test}

\subsection{Performance in competition}

In order to compare performance of the Kočenda test with other tests for nonlinearity and chaos we have exploited the study of Barnett et al. (1997) who performed a well-known single-blind controlled competition to compare the power of five highly regarded tests for nonlinearity or chaos against various alternatives. ${ }^{14}$ This approach allows us to distinguish which of the three $\varepsilon$-ranges maximizes the power of the test as well. This way, selection of the appropriate range loses its mystery.

In order to facilitate accessibility of our results we briefly outline the above single-blind competition. Despite the fact that the study of Barnett et al. (1997) is widely known, we urge consulting the original source for exhaustive details. The data used in this competition were simulated by five different generating specifications at two sample sizes. The "small" sample size contains 380 and "large" sample size 2000 observations. The samples were generated by the following five models:

1. Fully deterministic, chaotic Feigenbaum recursion (FEIG) of the form:

$$
y_{t}=3.57 y_{t-1}\left(1-y_{t-1}\right) \text {, }
$$

where the initial condition was set at $y_{0}=0.7$;

2. A generalized autoregressive conditional heteroscedasticity model (GARCH) of the form:

$$
y_{t}=h_{t}^{1 / 2} u_{t},
$$

where $h_{t}$ is defined by $h_{t}=1+0.1 y_{t-1}^{2}+0.8 h_{t-1}$, with $h_{0}=1$ and $y_{0}=0$;

3. A nonlinear moving average model (NLMA) of the form:

$$
y_{t}=u_{t}+0.8 u_{t-1} u_{t-2}
$$

4. An autoregressive conditional heteroscedasticity model (ARCH) of the form:

$$
y_{t}=\left(1+0.5 y_{t-1}^{2}\right)^{1 / 2} u_{t},
$$

\footnotetext{
${ }^{13}$ This is similar to the case of the BDS test.

${ }^{14}$ We acknowledge that Brock, Hsieh, and LeBaron (1993) performed similar tests but these were done mainly on the BDS test and as such they are less suitable as a point of reference for our further purpose.
} 
with the value of the initial observation set at $y_{0}=0$;

5. An autoregressive moving average model (ARMA) of the form:

$$
y_{t}=0.8 y_{t-1}+0.15 y_{t-2}+u_{t}+0.3 u_{t-1} \text {, }
$$

with $y_{0}=1$ and $y_{1}=0.7$.

The white noise disturbances, $u_{t}$, in the four stochastic models were sampled independently from a standard normal distribution and were generated using the fast acceptance-region algorithm of Kinderman and Ramage (1976), with the initial seed value set by the clock of the computer at the time the program was run. Of the five data generating models, specification (5.1) is chaotic and noise free, whereas the other specifications represent stochastic processes. ${ }^{15}$

The five tests that were used in the competition are the following: Hinich bispectral test in the frequency domain of flatness of the bispectrum, which is a test of the null hypothesis that the skewness function is flat, and hence that there is a lack of third order nonlinear dependence (for details see Hinich, 1982); BDS test for implicit evidence of nonlinearity. This is a test of the null hypothesis of iid (for details see Brock, Dechert, Scheinkman, and LeBaron, 1996); NEGM nonparametric test for positivity of the maximum Lyapunov exponent, which is a direct test for chaos (for details see Nychka, Ellner, Gallant, and McCaffrey, 1992); White test for nonlinearity, a test of the null hypothesis of the linearity in the mean (for details see White, 1989a, b; Lee, White, and Granger, 1993; Jungeilges, 1996); Kaplan test for nonlinearity, which is a test of the null hypothesis of linearity of the dynamics found in the data (for details see Kaplan, 1994).

Following the strategy of Barnett et al. (1997) we have used the same samples of the data that were used for the blind competition and run the Kočenda test on them; we have downloaded all ten data samples generated by models (5.15.5) from the Working Paper Archive maintained at Washington University. ${ }^{16}$ The results are presented in Table 6.

\footnotetext{
${ }^{15}$ For exhaustive details on models, data generating, as well as discussion on particular processes, see the original paper of Barnett et al. (1997).

${ }^{16}$ The web address of the data is http://econwpa.wustl.edu/eprints/data/papers/9510/9510001.abs
} 
For the most restrictive interval $(0.25 \sigma, 1.00 \sigma)$ and small sizes of the data the test was unable to confidently reject the iid hypothesis in case of GARCH, NLMA, and ARCH processes. Poor performance of the test in the case of the $\mathrm{ARCH}$ process occurred at embedding dimensions of 6 and higher; this range of values is associated with a higher dispersion of critical values (see Section 3.3). For two additional intervals, $(0.50 \sigma, 1.50 \sigma)$ and $(0.25 \sigma, 2.00 \sigma)$, the test rejected the iid hypothesis correctly at the $1 \%$ level for all processes and both sample sizes. This result is very encouraging since rejection of the iid null could also be made at all embedding dimensions; thus, the procedure has not left a void in inference with respect to both subjectively selected parameters of the test. Note that both sample sizes of competition data (380 and 2000) are different than sizes for which we generated critical values $(500,1000$, and 2500). For small (380) and large (2000) samples the closest critical values for sizes of 500 and 2500 observations were used, respectively.

We knew the nature of the data beforehand and therefore we did not perform a blind competition in the strictest sense. On the other hand, human factor enters the execution of the Kočenda test only in selecting $\varepsilon$-range and embedding dimensions; this becomes obvious later when we introduce new userfriendly and fast software to perform the test. By running the test in all three $\varepsilon$ ranges, each time for nine embedding dimensions, we eliminated potential reservations concerning our results. Further, since original data as well as our software are freely available, within minutes our findings can be easily replicated and verified.

To summarize: our results show that the test performance is very satisfactory since with a correctly selected $\varepsilon$-range it performs equally or better than the tests included in the competition performed by Barnett et al. (1997). ${ }^{17}$

\footnotetext{
${ }^{17}$ The following summary of the competition results comes from from section 9.1 Overview of Barnett et al. (1997). The Hinich bispectrum test was correct in three out of the five cases and failed in two of the cases with the small sample. With the large sample, the test was correct in three of the five cases, failed in one case, and was ambiguous in one case. The associated Gaussianity test, is a test of a necessary and not sufficient condition for Gaussianity and hence can reject but not accept. Judging the test on its rejections of Gaussianity, the small sample results produced only two rejections, and both were correct rejections. With the small sample, the test produced four rejections, and all four were valid rejections. With the small sample, the BDS test was correct in
} 
Further, the time needed to run the test with our new software is negligible.

\subsection{Power tests}

In addition to the performed competition we decided to verify performance of the test with multiple data sets by proceeding with a series of power tests. Power tests allow for further assessment of performance as well as enable us to establish a basis for correct selection of the $\varepsilon$-range.

In order to show ability of the test to correctly distinguish between truly random and random-like data we have performed a series of power tests to judge the performance at a $5 \%$ significance level, thus fixing the probability of the „first-type“ error. When the test is applied to the random-like data, the relative number of non-rejections of the null hypothesis $\left(\mathrm{H}_{0}\right.$ : data are iid) at the given significance level corresponds to the probability that the test is subject to the „second-type“ error-not rejecting the null hypothesis when it is not true. The smaller the probability of the „second-type“ error (probability of the „first-type“ error being fixed) is, the greater the power of the test.

To conduct the power tests we pursued the following strategy. For each of the five models described in specifications (5.1-5.5), and used by Barnett et al. (1997), we have generated 1000 samples of data. ${ }^{18}$ The data were generated in three sizes of 500, 1000, and 2500 observations. We have used all samples to perform a battery of power tests; the results are reported in Tables 7-9. For better accessibility we report cumulative results of the power tests as a percentage of $\mathrm{H}_{0}$ rejections; the percentage when the test correctly rejects the null hypothesis since tested data are anything but iid.

Across all proximity ranges as well as sample sizes the test always

two cases out of five and ambiguous in the other three. With the large sample, the test was correct in all five cases. The NEGM test was correct in all five small sample cases and all five large sample cases. In the small sample cases, White's test was correct in four out of the five cases, and failed in the remaining case. In the large sample cases, White's test again was correct in four out of the five cases, and failed in one case. Kaplan's test was correct in all five cases both with the small samples and the large samples.

${ }^{18}$ Because the Feigenbaum process is deterministic we have replicated 1000 times only the four other processes, to be precise. Since competition performed by Barnett et al. (1997), understandably, does not contain power tests of participating tests, we do not offer any comparison in this respect. 
accurately rejects the null hypothesis for FEIG and ARMA processes. For the remaining processes the power of the test uniformly improves with the sample size as one would expect. ${ }^{19} \mathrm{GARCH}, \mathrm{ARCH}$, and NLMA processes pose some challenge to the test at sample size of 500 observations; the power of the test dramatically improves for ARCH and NLMA processes when samples of 1000 and 2500 observations are used. An interesting picture emerges when the power of the test is compared among the three ranges of the proximity parameter. The power is lowest for interval $(0.25 \sigma, 1.0 \sigma)$ but improves radically for intervals $(0.5 \sigma, 1.5 \sigma)$ and $(0.25 \sigma, 2.0 \sigma)$. For these two intervals the power of the test is extremely high, above $90 \%$ in most cases even for the small sample size of 500 observations; an exception is the power in the GARCH process. The power of the test is highest for both wide intervals and large sample size (2500 observations) in all five processes; it is near $100 \%$ of correct rejections for the GARCH process and precisely $100 \%$ for remaining processes.

\subsection{Further power tests on chaotic data with noise}

For the sake of consistency the previous power tests were performed on the set of processes used in Barnett at al. (1997). We performed further power tests on other chaotic processes with additive noise. In order to keep the extent of work manageable we have chosen two standard non-univariate chaotic systems to generate the data; both were additively contaminated with noise (the results of these additional power tests are presented in Tables 10-12).

First, we have chosen the Hénon (1976) map, which is a bivariate chaotic system described by a pair of difference equations; for our purpose we used a collapsed version of the original system given by specification as in Lai and Chen (2003):

$$
y_{t+1}=1+0.3 y_{t-1}-1.4 y_{t}^{2}
$$

which was further contaminated by noise. The new noisy chaotic series $x_{t}$ was constructed as $x_{t}=y_{t}+u_{t}$ where $y_{t}$ satisfies (5.6) and $u_{t}$ is independently and

\footnotetext{
${ }^{19}$ This finding is in line with results reported by Hsieh and LeBaron (1991) who have found that type I error is large with the BDS test when the sample size is small.
} 
normally distributed with mean 0 and variance 0.04 .

The test recorded a $100 \%$ rejection rate of the iid hypothesis correctly for both chaotic and noisy chaotic series for all three $\varepsilon$-ranges used.

Further, we opted for the Lorenz (1963) map, which is a trivariate chaotic system described by a system of differential equations. However, for our purpose we used a more intricate specification of the system of 10 differential equations suggested by Lorenz (1996) and Emanuel and Lorenz (1998). In general, it is a system of $N$ differential equations with $N$ variables specified as:

$$
\dot{x}_{i}=-\left(x_{i-2}+x_{i+1}\right) x_{i-1}-x_{i}+f, \text { where } i=1,2, \ldots, N \text {. }
$$

To make these equations meaningful, it was set $x_{-1}=x_{N-1}, x_{0}=x_{N}$ and $x_{N+1}=x_{1}$. The variables of the system are scaled so that the coefficients of the quadratic and linear terms are unity. For the purpose of our simulation we consider $N=10$. Like the previous case of the Hénon map we contaminated data with noise by adding error process $u_{t}$, where $u_{t}$ is independently and normally distributed with mean 0 and variance 0.04 as in in Lai and Chen (2003).

The test recorded a $100 \%$ rejection rate of the iid hypothesis correctly for both chaotic and noisy chaotic series for all three $\varepsilon$-ranges used.

\subsection{Range selection recommendation}

The results of the power tests combined with the findings on sensitivity of the critical values to the $\varepsilon$-range choice enable us to formulate the following recommendations.

Unless assumptions of a research project dictate otherwise, the intervals $(0.50 \sigma, 1.50 \sigma)$ and $(0.25 \sigma, 2.00 \sigma)$ should be used. If no preferences associated with research motivations are set, we suggest avoiding the use of the $(0.25 \sigma$, $1.00 \sigma$ ) range since the power of the test is lower than for the other two intervals (negatively biased estimator).

For "short" data samples the $(0.50 \sigma, 1.50 \sigma)$ range should be used as a preferred choice, especially in cases when a set of the lower embedding dimensions is used, as is common practice among researchers. Range $(0.50 \sigma$, $1.50 \sigma$ ) has slightly better power over embedding dimensions $m=2-5$ than the 
range $(0.25 \sigma, 2.00 \sigma)$, which has better power over dimensions $m=6-9$. Thus, range $(0.50 \sigma, 1.50 \sigma)$ should be used for tests carried over embedding dimensions $m=2-5$ and the range $(0.25 \sigma, 2.00 \sigma)$ for tests carried over the whole set of dimensions, e.g. $m=2-9$. However, since testing at high levels of embedding dimension $m$ (when $m$ is higher than 5 ) is often questionable due to reasons articulated earlier, the range $(0.50 \sigma, 1.50 \sigma)$ may be used as a convenient template option.

\subsection{The bootstrap method}

The critical values in Section 3 were tabulated under the assumption of a standard normal distribution. This is a sensible assumption when real data are meant to be scrutinized by the test. The two kinds of most widely used data exploited in the literature on nonlinear dynamics are exchange rates and stock prices (see Hsieh, 1989 and 1991 for comprehensive assessments); further typical data are returns on bonds and treasury as well as inflation rates (see Hiemstra and Kramer, 1997). The residuals coming from models aiming to capture nonlinear dynamics in such data are usually subject to testing for being iid since most frequently they are normally distributed but often still exhibit nonlinearities (e.g. they are not independent).

To illustrate the point we present histograms of several series of residuals from nonlinear models of exchange rates as well as stock prices. For exchange rates we use several standardized residual series from models by Kugler and Lenz (1990, 1993) and Brock, Hsieh, and LeBaron (1993). ${ }^{20}$ The histograms of

\footnotetext{
${ }^{20}$ Kugler and Lenz (1990) analyzed the nonlinear dependence of weekly exchange rate changes for four currencies against the US (the rate of change of the $\log$ exchange rate $x_{t}=\Delta \log S_{t}$ ). The data were corrected to account for the present $\mathrm{ARCH}$ process by transformation into the $\mathrm{ARCH}$ corrected rate of changes in the form $\Delta \log S_{t}^{h}=\Delta \log S_{t}\left(\hat{\alpha}_{0}+\sum_{\tau=1}^{6} \hat{\alpha}_{\tau} \Delta \log S_{t-\tau}^{2}\right)^{-0.5}$.

Kugler and Lenz (1993) analyzed the nonlinear dependence of weekly exchange rate changes for ten currencies against the US dollar. They estimated the GARCH-M model as

$\Delta \log S_{t}=\beta_{0}+\sum_{\tau=1}^{3} \beta_{\tau} \Delta \log S_{t-\tau}+\beta_{4} \sqrt{h_{t}}+\eta_{t}$, where $h_{t}=\alpha_{0}+\alpha_{1} \eta_{t-1}^{2}+\alpha_{2} h_{t-1}$ and $\eta_{t}=\varepsilon_{t} \sqrt{h_{t}}$.

Brock, Hsieh, and LeBaron (1993) analyzed the daily closing bids for the five major currencies in US dollars. They estimated the GARCH model specified as
} 
distributions of particular residuals are presented in Figure 2.

For stock prices we use standardized residuals from models using stock price indices from Standard \& Poors 500 Index and Dow Jones Industrial Average Index. ${ }^{21}$ These stock indices represent two of the most commonly used benchmarks of overall stock market developments and were used in numerous studies; to name just a few, S\&P500 stock index was used in studies of Harris (1989), Brorsen and Yang (1994) or Bollerslev and Mikkelsen (1999); likewise, the Dow Jones stock index was used by Hiemstra and Jones (1994), Andersen et al. (2001) or Engle and Patton (2001), among others. Histograms in Figure 3 show the distribution of standardized residuals coming from the EGARCH model used by Hsieh (1991) for weekly S\&P500 returns and from the GARCH model used by Engle and Patton (2001) for daily Dow Jones returns. ${ }^{22}$

The histograms of residuals for both exchange rates and stock indices clearly show that series approximate standard normal distribution and do not exhibit any significant departures or distortions. Yet we know that many of the real economic series are not iid, similar to artificial nonlinear data. Still their distributions may look perfectly normal, as is the case of four processes used in the study of Barnett et al. (1997) whose distributions are presented in Figure 4.

Hence, for the real economic data that we just introduced for illustrative purposes, the use of tabulated critical values is wholly appropriate. However, this does not need to be the case if data exhibit excessive departure from standard

$r_{t}=\beta_{0}+\sum_{i=1}^{j} \beta_{i} r_{i-1}+\beta_{M} D_{M, t}+\beta_{T} D_{T, t}+\beta_{W} D_{W, t}+\beta_{R} D_{R, t}+\beta_{H} D_{H}+u_{t}$, where, $u_{t} \mid \Omega_{t-1} \sim D\left(0, h_{t}\right)$, and variance equation is $h_{t}=\phi_{0}+\psi u_{t-1}^{2}+\phi h_{t-1}+\phi_{M} D_{M, t}+\phi_{T} D_{T, t}+\phi_{W} D_{W, t}+\phi_{R} D_{R, t}+\phi_{H} D_{H}$, where $r_{t}$ is the rate of change of the nominal exchange rate at time $t, D_{M, t}, D_{T, t}, D_{W, t}$, and $D_{R, t}$, are dummy variables for Monday, Tuesday, Wednesday, and Thursday; and $D_{H}$ is the number of holidays between two successive trading days excluding weekends.

${ }^{21}$ Historical series of the Standard \& Poors 500 Index (SPC) are available at http://www.investmenttool.com/. Historical series of The Dow Jones Industrial Average Index (DJI) are available at http://averages.dowjones.com/.

${ }^{22}$ Hsieh (1991) analyzed whether ARCH-type models are able to capture all the nonlinear dependencies in the stock returns. He used EGARCH model specified as $\log \sigma^{2}=\phi_{0}+\phi\left|x_{t-1} / \sigma_{t-1}\right|+\psi \log \sigma_{t-1}^{2}+\not x_{t-1} / \sigma_{t-1}$, where $x_{t} \sim N\left(0, \sigma^{2}\right)$.

Engle and Patton (2001) considered GARCH model to forecast volatility of return on the asset $R_{t}=m_{t}+\sqrt{h_{t}} \varepsilon_{t}$, opting for GARCH $(1,1)$ specification $h_{t}=\omega+\sum_{\tau=1}^{p} \alpha_{\tau}\left(R_{t-\tau}-\mu\right)^{2}+\sum_{\tau=1}^{q} \beta_{\tau} h_{t-\tau}$. 
normal. Belaire-Franch (2003) has shown that if there is a large excess kurtosis in the data $(\alpha=1.2)$, the iid hypothesis would be erroneously rejected by the test very frequently. He argues that the bootstrapping method (the random shuffle) should be used to generate particular critical values for each series analyzed to avoid asymptotically biased critical values. Specifically, the given sample of size $T$ is taken as the population and samples of size $T$ are drawn from the "population" with replacement. The samples are used to obtain an estimate, called the bootstrap distribution of the true population distribution. By replacing the true population distribution by the bootstrap distribution we may obtain an estimate of the distribution of an estimator or test statistic of interest.

The departure from normality due to a large kurtosis (as in Belaire-Franch, 2003) or contaminated normal distribution with a very large contaminating variance (e. g. $\mathrm{K}^{2}=100$ as in Ronchetti and Trojani, $2003^{23}$ ), surely justifies using the bootstrap to generate custom-made critical values in the case of artificial, computer-generated time series. Such radical departures from normality are not typical for real economic data or the residuals coming from nonlinear models that use such economic data. For that reason, the significance of Kočenda's statistic should be evaluated on quantiles generated from the standard normal distribution only when the departure of tested time series from the normal distribution is very small (as in the ample examples given above). In other cases we suggest using the bootstrap method as discussed in Belaire-Franch (2003).

\section{Software}

In order to facilitate running the test we provide fast and user-friendly software to calculate values of the test statistics. In line with the previous exposition, a researcher has three choices for range of epsilons: $(0.25 \sigma ; 1.00 \sigma),(0.50 \sigma ; 1.50 \sigma)$ or $(0.25 \sigma ; 2.00 \sigma)$. This is done at nine embedding dimensions $m=2, \ldots, 10$. The program automatically suggests the optimal set of critical values based on the

\footnotetext{
${ }^{23}$ They used data generated from contaminated normal distribution $C N\left(\varepsilon, \mathrm{K}^{2}\right)$ given by distribution function $F(x)=(1-\varepsilon) \Phi(x)+\varepsilon \Phi\left(\frac{x}{K}\right)$, where $\Phi(x)$ is a cumulative distribution function of a standard normal random variable.
} 
sample size, compares the computed values with built-in critical values (those reported in Tables 2-4), and notes statistical significance as well reject/no reject result.

There is also a built-in data diagnostic table, which provides description of the data: number of observations, mean, standard deviation, spread and the standard deviation divided by the spread. For an even more detailed view of the series tested, one can use the histogram button: a new pop-up window opens and a histogram (up to 50 dividing bins) is plotted.

An advanced menu in the program allows one to compute a test statistic for arbitrary values of $\varepsilon$-range. Please note that in this case the built-in critical values should not be used and it is suggested to proceed with the bootstrapping method in order to generate an appropriate set of critical values. For more experienced users and those interested in doing simulations, a fast engine was compiled separately and can be used to perform Monte Carlo studies or can be built in as a part of some other program.

The program is user friendly with a self-explanatory design. Although personal computers at the present time are very fast, computation on slower computers with a large number of observations can take several minutes. For illustration, the values of the test statistic with a sample of 500 observations are computed within seconds even for a slow computer; computation of the test statistics for nine embedding dimensions and 2500 observations takes approximately 50 seconds for $2 \mathrm{GHz}$ Pentium 4 processor.

The program requires a Windows 98/2000/NT/XP environment. It is posted on our webpage as freeware, subject to appropriate citation. No warranty of any kind is expressed or implied. More information can be found in a "readme" file that is part of the program.

\section{Conclusion}

In this paper we tabulated new sets of critical values for the test of Kočenda (2001) to allow for better selection of proximity parameters interval. We also provided a sensitivity check to the robustness of critical values with respect to the 
choice of range of proximity parameters. Further, we performed a series of power tests.

The results of the power tests combined with the findings on sensitivity of the critical values to the $\varepsilon$-range choice suggest that unless assumptions of a research project dictate otherwise, the intervals $(0.50 \sigma, 1.50 \sigma)$ and $(0.25 \sigma, 2.00 \sigma)$ should be used. If no preferences associated with research motivations are set, we suggest avoiding the use of the $(0.25 \sigma, 1.00 \sigma)$ range since the power of the test is lower than for the other two intervals (negatively biased estimator). For "short" data samples the $(0.50 \sigma, 1.50 \sigma)$ range should be used as a preferred option. Range $(0.50 \sigma, 1.50 \sigma)$ has slightly better power over embedding dimensions $m=2-5$ than the range $(0.25 \sigma, 2.00 \sigma)$, which has better power over dimensions $m=6-9$. Thus, range $(0.50 \sigma, 1.50 \sigma)$ should be used for tests carried over embedding dimensions $m=2-5$ and the range $(0.25 \sigma, 2.00 \sigma)$ for tests carried over the whole set of dimensions, e.g. $m=2-9$. However, since testing at high levels of embedding dimension $m$ (when $m$ is higher than 5) is often questionable due to reasons articulated earlier, the range $(0.50 \sigma, 1.50 \sigma)$ may be used as a convenient template option.

Further, we introduced a new compact program to run the test as well as simulations. The software is very fast, user-friendly, and may be downloaded from http:/home.cerge-ei.cz/kocenda/software/ as freeware, subject to appropriate citation. 


\section{Appendix}

Proposition: Slope coefficient estimates $\beta_{m}$ are smaller than or equal to respective embedding dimension $m$, i.e. $\beta_{m} \leq m$.

Proof: We assume in (2.1) that under the null hypothesis the series $x_{t}$ is randomly generated according to density function $f$. Then for small $\varepsilon$

$$
\frac{P\left(\left|x_{t}-x_{s}\right|<\varepsilon\right)}{\varepsilon}=\frac{1}{\varepsilon} \int_{-\infty}^{\infty} f\left(x_{t}\right) \int_{\left(x_{t}-\varepsilon\right)}^{\left(x_{t}+\varepsilon\right)} f\left(x_{s}\right) \mathrm{d} x_{s} \mathrm{~d} x_{t} \cong 2 \int f\left(x_{t}\right)^{2} \mathrm{~d} x_{t} \equiv k .
$$

By the virtue of equation (2.1) for sufficiently small $\varepsilon$ it holds that

$$
E\left(C_{m, T}(\varepsilon)\right)=2 \sum_{t=1}^{T_{m}-1} \sum_{s=t+1}^{T_{m}} P\left(\max _{i=0, \ldots, m-1}\left|x_{t+i}-x_{s+i}\right|<\varepsilon\right) /\left(T_{m}\left(T_{m}-1\right)\right) \cong 2(\varepsilon k)^{m} .
$$

It follows that

$$
\lim _{\substack{T \rightarrow \infty \\ \varepsilon \rightarrow 0}} \frac{\ln E\left(C_{m, T}(\varepsilon)\right)}{\ln (\varepsilon)}=\lim _{\varepsilon \rightarrow 0} \frac{m \ln (\varepsilon k)}{\ln (\varepsilon)}=m .
$$

Besides

$$
\lim _{\varepsilon \rightarrow 0} \frac{\ln P\left(\left|x_{t}-x_{s}\right|<\varepsilon\right)}{\ln (\varepsilon)}=1
$$

By Jensen's inequality

$$
E\left(\ln \left(C_{m, T}(\varepsilon)\right)\right) \leq \ln \left(E\left(C_{m, T}(\varepsilon)\right)\right) .
$$

Combining previous results, namely (A.3), (A.4), and (A.5), it follows that for large $T$ and small $\varepsilon$

$$
E\left(\ln \left(C_{m, T}(\varepsilon)\right)\right) \leq \ln \left(E\left(C_{m, T}(\varepsilon)\right)\right) \cong \ln P\left(\left|x_{t}-x_{s}\right|<\varepsilon\right) \cong m \ln (k)+m \ln (\varepsilon) .^{24} \text { (A.6) }
$$

As in the regression

$$
\ln \left(C_{m, T}(\varepsilon)\right)=\alpha+\beta \ln (\varepsilon)+e,
$$

the left hand variable has a negative bias from

$$
m \ln (k)+m \ln (\varepsilon) .
$$

Therefore, the smaller $\varepsilon$, the smaller the bias, so that the estimated coefficient satisfies

$$
E[\beta] \leq m .
$$

QED

\footnotetext{
${ }^{24}$ Equality holds in linear cases.
} 


\section{References}

Aguirre, A., Aguirre, L.A., 2000. Time Series Analysis of Monthly Beef Cattle Prices with Nonlinear Autoregressive Models. Applied Economics, 32(3), 265-75.

Andersen, T. G., Bollerslev, T., Diebold, F. X., and Ebens, H., 2001. The Distribution of Realized Stock Return Volatility. Journal of Financial Economics, 61(1), 43-76.

Andreou, A. S., Pavlides, G., Karytinos, A, 2000. Nonlinear Time-Series Analysis of the Greek Exchange-Rate Market. International Journal of Bifurcation and Chaos in Applied Sciences and Engineering, 10(7), 1729-1759.

Barnett, W.A., Gallant, A.R., Hinich, M.J., Jungeilges, J.A., Kaplan, D.T., Jensen, M.J., 1997. A single-blind controlled competition among tests for nonlinearity and chaos. Journal of Econometrics, vol. 82, pp. 157-192.

Belaire-Franch, J., 2003. A Note on Resampling the integration Across the Correlation Integral with Alternative Ranges. Econometric Reviews, 22(4), 337349.

Bodman, P. M. , 2001. Steepness and deepness in the Australian macroeconomy. Applied Economics, 33(3).

Bollerslev, T., and Mikkelsen, H. O., 1999. Long-Term Equity Anticipation Securities and Stock Market Volatility Dynamics. Journal of Econometrics, 92(1), 75-99.

Brock, W., 1988. Nonlinearity and Complex Dynamics in Economics and Finance in Anderson, P. W., Arrow, K. J., and Pines, D., editors, 1988, The Economy as an Evolving Complex System, Santa Fe Institute Studies in the Sciences of Complexity, v. 5, Addison-Wesley Publishing Company

Brock, W., Dechert, W., Scheinkman, J., LeBaron, B., 1996. A Test for Independence Based on the Correlation Dimension. Econometric Reviews, 15, 197-235.

Brock, W. A., Hsieh, D. A., and LeBaron, B., 1993. Nonlinear Dynamics, Chaos, and Instability: Statistical Theory and Economic Evidence, MIT Press, Cambridge, Massachusetts, Third edition.

Brooks, C., 1999. Portmanteau Model Diagnostics and Tests for Nonlinearity: A Comparative Monte Carlo Study of Two Alternative Methods. ComputationalEconomics, 13(3),249-63.

Brooks, C., Henry, O.T., 2000. Can portmanteau nonlinearity tests serve as 
general miss-specification tests?: Evidence from symmetric and asymmetric GARCH models. Economics Letters, 67(3), 245-251.

Brooks, C.; Heravi, S.M., 1999. The Effect of (Mis-Specified) GARCH Filters on the Finite Sample Distribution of the BDS Test. Computational Economics, 13(2), 147-62.

Brorsen, B. W., and Yang, S. R., 1994. Nonlinear Dynamics and the Distribution of Daily Stock Index Returns. Journal of Financial Research, 17(2), 187-203.

Cecen, A.A., Erkal, C., 1996. Distinguishing between stochastic and deterministic behavior in foreign exchange rate returns: Further evidence. Economics Letters, 51(3), 323-329.

Chappell, D., Padmore, J., Ellis, C., 1996. A Note on the Distribution of BDS Statistics for a Real Exchange Rate Series. Oxford Bulletin of Economics and Statistics, 58(3), 561-65.

Chen, Y., Kuan, C., 2002. Time irreversibility and EGARCH effects in US stock index returns. Journal of Applied Econometrics, 17(5).

Chwee, V., 1998. Chaos in Natural Gas Futures?, Energy Journal, 19(2), 149-164.

Collings, B. J., 1987. Compound Random Number Generators. Journal of the American Statistical Association, 82, Theory and Methods, 525-527.

de Lima, P., 1998. Nonlinearities and Nonstationarities in Stock Returns. Journal of Business and Economic Statistics, 16(2), 227-236.

de Lima, P., 1992. A Test for IID Based upon the BDS Statistic, Department of Economics, Johns Hopkins University.

de Lima, P., 1996. Nuisance Parameter Free Properties of Correlation Integral Based Statistics. Econometric Reviews, 15(3), 237-59.

Dechert, W., 1994. The Correlation Integral and the Independence of Gaussian and Related Processes, University of Wisconsin at Madison, SSRI Working Paper 9412.

Díaz, A.F.,Grau-Carles, P., Mangas, L.E., 2002. Nonlinearities in the exchange rates returns and volatility. Physica A: Statistical Mechanics and its Applications, $316,469-482$.

Diks, C., 2003. Detecting serial dependence in tail events: a test dual to the BDS test. Economics Letters, 79(3), 319-324. 
Emanuel, K. and Lorenz, E., 1998. Optimal Sites for Supplementary Weather Observations: Simulation with a Small Model. Journal of the Atmospheric Sciences, 55, 399-414.

Engle, R. F., and Patton, A. J., 2001. What Good Is a Volatility Model? Quantitative Finance, 1(2), 237-45.

Fishman, G. S., and Moore, L. R., 1982. A Statistical Evaluation of Multiplicative Congruential Random Number Generators with Modulus 231-1. Journal of the American Statistical Association, 77, Theory and Methods, 129-136.

Grassberger, P., and Procaccia, I., 1983. Measuring the Strangeness of Strange Attractors. Physica 9D, 189-208.

Harris, L., 1989. S\&P 500 Cash Stock Price Volatilities. Journal of Finance, 44(5), 1155-75.

Hellekalek, P., 1995. Inversible pseudorandom number generators: concept, results, and links. Proceedings of the 1995 Winter Simulation Conference, pp. 255-262.

Hénon, M., 1976. A two-dimensional mapping with strange attractor. Communications in Mathematical Physiscs 50, 69-77.

Hiemstra, C., and Jones, J. D., 1994. Testing for Linear and Nonlinear Granger Causality in the Stock Price-Volume Relation. Journal of Finance, 49(5), 163964.

Hiemstra, C., and Kramer, C., 1997 Nonlinearity and Endogeneity in Macro-Asset Pricing, Studies in Nonlinear Dynamics and Econometrics: Vol. 2: No. 3, Art. 1.

Hinich, M.J., 1982. Testing for Gaussianity and linearity of a stationary time series. Journal of Time Series Analysis 3(3), 169-176

Hsieh, D. A., 1989. Testing for Nonlinear Dependence in Daily Foreign Exchange Rates, Journal of Business 62, 339-368.

Hsieh, D. A., 1991. Chaos and Nonlinear Dynamics: Application to Financial Markets. Journal of Finance 46, 1839-1877.

Hsieh, D. A., 1993. Implications of Nonlinear Dynamics for Financial Risk Management. Journal of Financial and Quantitative Analysis, 28(1), 41-64.

Hsieh, D. A., and LeBaron, B., 1988. The BDS Test. Later published as the Chapter 2, in Brock, W. A., Hsieh, D. A., and LeBaron, B., 1993. Nonlinear Dynamics, Chaos, and Instability: Statistical Theory and Economic Evidence, 
MIT Press, Cambridge, Massachusetts, Third edition.

Johnson, D., McClelland, R., 1998. A General Dependence Test and Applications. Journal of Applied Econometrics, 13(6), 627-644.

Jungeilges, J.A., 1996. Operational charactristics of White's test for neglected nonlinearities. In: Barnett, W., Kirman, A., Salmon, M. (Eds.), Nonlinear Dynamics in Economics. Cambridge University Press, Cambridge, pp. 219-266.

Kanzler, L., 1999. Very Fast and Correctly Sized Estimation of the BDS Statistic. Manuscript. Christ Church and Department of Economics, University of Oxford (http://papers.ssrn.com/sol3/papers.cfm?abstract_id=151669).

Kaplan, D.T., 1994. Exceptional events as evidence for determinism. Physica D 73, 38-48.

Kinderman, A.J., Ramage, J.G., 1976. Computer generation of normal random numbers. Journal of the American Statistical Association 71, 893-896.

Kočenda, E., 1996. Volatility of a Seemingly Fixed Exchange Rate. Eastern European Economics, 34, 6, 37-67.

Kočenda, E., 2001. An Alternative to the BDS Test: Integration across the Correlation Integral. Econometric Reviews, 20(3), 337-351.

Krämer, W., Runde, R., 1997. Chaos and the compass rose. Economics Letters, 54(2), 113-118.

Kugler, P., and Lenz, C., 1990. Sind Wechselkursfluktuationen zufullig oder chaotisch? (Are Exchange Rate Fluctuations Random or Chaotic?). Schweizerische Zeitschrift fhr Volkswirtschaft und Statistik, 126(2), 113-128.

Kugler, P., and Lenz, C., 1993. Chaos, ARCH, and the Foreign Exchange Market: Empirical Results from Weekly Data. Rivista Internazionale di Scienze Economiche e Commerciali, 40(2), 127-140.

L'Ecuyer, P., 2004. Random Number Generation. In: Gentle, J. E., Haerdle W., Mori Y. (Eds.), Handbook of Computational Statistics. Springer-Verlag.

Lai, D., Chen, G., 2003. Distribution of the Estimated Lyapunov Exponents From Noisy Chaotic Time Series. Journal of Time Series Analysis, 24(6): 705-720

Lee, T.H., White, H., Granger, C., 1993. Testing for neglected nonlinearities in time series models. Journal of Econometrics 56, 269-290.

Lorenz, E., 1963. Deterministic nonperiodic flow. Journal of the Atmospheric 
Sciences 20, 130-141.

Lorenz, E., 1996. Predictability - a problem partly solved. In Palmer, T. (ed.), Predictability. European Centre for Medium-Range Weather Forecasting, Shinfield Park, Reading, UK.

Mahajan, A., Wagner, A.J., 1999. Nonlinear dynamics in foreign exchange rates. Global Finance Journal, 10(1), 1-23.

Muckley,C., 2004. Empirical Asset Return Distributions: Is Chaos the Culprit? Applied Economics Letters. 11(2): 81-86

McKenzie, M.D., 2001. Chaotic behavior in national stock market indices: New evidence from the close returns test. Global Finance Journal, 12(1), 35-53.

Nychka, D., Ellner, S., Gallant, R., McCaffrey, D., 1992. Finding chaos in noisy systems. Journal of the Royal Statistical Society B 54, 399-426.

Opong, K.K., Mulholland, G., Fox, A.F., Farahmand, K., 1999. The behaviour of some UK equity indices: An application of Hurst and BDS tests. Journal of Empirical Finance, 6(3), 267-282.

Panagiotidis, T., 2003. Market Efficiency and the Euro: The case of the Athens Stock Exchange. Discussion Paper 03-08, Department of Economics and Finance, Brunel University.

Ronchetti, E. and Trojani, F., 2003. Robust Inference with GMM Estimators, Journal of Econometrics, 101, 37-69.

Rothman, P., 1992. The Comparative Power of the TR Test Against Simple Threshold Models. Journal of Applied Econometrics, 7, Supplement: Special Issue on Nonlinear Dynamics and Econometrics, S187-S195.

Serletis, A., Gogas, P., 1997. Chaos in East European black market exchange rates. Research in Economics, 51(4), 359-385

White, H., 1989a. Some asymptotic results for learning in single hidden-layer feedforward network models. Journal of the American Statistical Association 84, 1003-1013.

White, H., 1989b. An additional hidden unit test for neglected nonlinearity in multilayer feedforward networks. In: Proceedings of the International Joint Conference on Neural Networks, vol. 2, IEEE Press, New York. pp. 451-455. 
Table 1

Summary of $\varepsilon$-ranges used in selected studies

\begin{tabular}{|c|c|c|}
\hline Year & The author of the study & $\begin{array}{l}\text { Used values of proximity parameter } \varepsilon \\
\text { ( } \varepsilon \text { as a fraction of standard deviation) }\end{array}$ \\
\hline 1989 & Hsieh & $0.25,0.50,0.75,1.00,1.25,1.50,2.00$ \\
\hline 1990 & Kugler and Lenz & $0.50,0.75,1.00,1.50$ \\
\hline 1991 & Hsieh & $0.25,0.50,1.00,1.50,2.00$ \\
\hline 1992 & Rothman & $0.50,1.00,1.25,1.50,2.00$ \\
\hline 1993 & Kugler and Lenz & 1.00 \\
\hline 1993 & Hsieh & $0.50,1.00,1.50,2.00$ \\
\hline 1996 & Brock, Dechert, Scheinkman, and LeBaron & 0.50 \\
\hline 1996 & Cecen and Erkal & 0.50 \\
\hline 1996 & de Lima & $1.00,1.25$ \\
\hline 1996 & Chappell, Padmore, and Ellis & $0.40,0.625,1.00,1.60$ \\
\hline 1996 & Kočenda & $0.50,1.00$ \\
\hline 1997 & Krämer and Runde & 1.00 \\
\hline 1997 & Serletis and Gogas & $0.50,1.00,1.50,2.00$ \\
\hline 1998 & Johnson and McClelland & 1.00 \\
\hline 1998 & Brock, Hsieh, and LeBaron & $0.50,0.75,1.00,1.25,1.50$ \\
\hline 1998 & Chwee & $0.50,1.00,1.50,2.00$ \\
\hline 1998 & de Lima & $0.50,0.75,1.00,1.25,1.50$ \\
\hline 1999 & Mahajan and Wagner & $0.50,0.75,1.00,1.25,1.50$ \\
\hline 1999 & Opong, Mulholland, Fox, and Farahmand & $0.50,1.00,1.50,2.00$ \\
\hline 1999 & Brooks & $1.00,1.50$ \\
\hline 1999 & Brooks and Heravi & $0.50,1.00,1.50,2.00$ \\
\hline 2000 & Brooks and Henry & $1.00,1.50$ \\
\hline 2000 & Andreou, Pavlides, and Karytinos & $0.50,1.00,1.50,2.00$ \\
\hline 2000 & Aguirre and Aguirre & $0.65,0.70,0.75,0.80,0.85,0.90$ \\
\hline 2001 & McKenzie & $0.50,1.00,1.50,2.00$ \\
\hline 2001 & Bodman & 1.00 \\
\hline 2002 & Díaz, Grau-Carles, and Mangas & 1.50 \\
\hline 2002 & Chen and Kuan & $0.75,1.00$ \\
\hline 2003 & Diks & several values between 0.50 and 1.50 \\
\hline 2003 & Panagiotidis & $0.50,1.00,2.00$ \\
\hline 2004 & Muckley & $0.50,1.00$ \\
\hline
\end{tabular}


Table 2

Quantiles of the slope coefficients $\beta_{m}$ for $\mathcal{E}$-range $(0.25 \sigma-1.00 \sigma)$

\section{A. Quantiles of the slope coefficients $\beta_{m}$ for a sample size of 500 observations}

\begin{tabular}{cccccccccc}
\hline Quantile & $\beta_{2}$ & $\beta_{3}$ & $\beta_{4}$ & $\beta_{5}$ & $\beta_{6}$ & $\beta_{7}$ & $\beta_{8}$ & $\beta_{9}$ & $\beta_{10}$ \\
\hline $0,5 \%$ & 1,850 & 2,736 & 3,547 & 4,252 & 4,897 & 5,418 & 5,787 & 5,934 & 5,531 \\
\hline $1,0 \%$ & 1,857 & 2,749 & 3,570 & 4,293 & 4,952 & 5,506 & 5,909 & 6,092 & 5,829 \\
\hline $2,5 \%$ & 1,865 & 2,767 & 3,610 & 4,353 & 5,036 & 5,629 & 6,092 & 6,354 & 6,185 \\
\hline $5,0 \%$ & 1,872 & 2,782 & 3,639 & 4,407 & 5,109 & 5,742 & 6,241 & 6,572 & 6,540 \\
\hline & & & & & & & & & \\
\hline $95,0 \%$ & 1,929 & 2,923 & 3,955 & 4,909 & 5,885 & 6,895 & 8,006 & 9,322 & 11,209 \\
\hline $97,5 \%$ & 1,933 & 2,936 & 3,987 & 4,957 & 5,965 & 7,017 & 8,202 & 9,660 & 11,997 \\
\hline $99,0 \%$ & 1,938 & 2,952 & 4,019 & 5,010 & 6,050 & 7,167 & 8,435 & 10,087 & 13,026 \\
\hline $99,5 \%$ & 1,941 & 2,963 & 4,041 & 5,046 & 6,107 & 7,279 & 8,611 & 10,425 & 13,747 \\
\hline
\end{tabular}

Note: " $m$ " denotes an embedding dimension. Based on 20,000 replications.

\section{B. Quantiles of the slope coefficients $\beta_{m}$ for a sample size of 1000 observations}

\begin{tabular}{cccccccccc}
\hline Quantile & $\beta_{2}$ & $\beta_{3}$ & $\beta_{4}$ & $\beta_{5}$ & $\beta_{6}$ & $\beta_{7}$ & $\beta_{8}$ & $\beta_{9}$ & $\beta_{10}$ \\
\hline $0,5 \%$ & 1,875 & 2,793 & 3,669 & 4,464 & 5,192 & 5,844 & 6,420 & 6,870 & 7,208 \\
\hline $1,0 \%$ & 1,878 & 2,799 & 3,682 & 4,486 & 5,225 & 5,898 & 6,501 & 6,996 & 7,358 \\
\hline $2,5 \%$ & 1,882 & 2,808 & 3,701 & 4,521 & 5,279 & 5,984 & 6,620 & 7,149 & 7,579 \\
\hline $5,0 \%$ & 1,886 & 2,816 & 3,718 & 4,557 & 5,329 & 6,051 & 6,715 & 7,293 & 7,765 \\
\hline & & & & & & & & & \\
\hline $95,0 \%$ & 1,916 & 2,888 & 3,893 & 4,890 & 5,826 & 6,770 & 7,747 & 8,777 & 9,905 \\
\hline $97,5 \%$ & 1,918 & 2,895 & 3,911 & 4,922 & 5,870 & 6,834 & 7,849 & 8,917 & 10,148 \\
\hline $99,0 \%$ & 1,921 & 2,902 & 3,931 & 4,960 & 5,927 & 6,908 & 7,966 & 9,096 & 10,458 \\
\hline $99,5 \%$ & 1,922 & 2,906 & 3,945 & 4,985 & 5,970 & 6,953 & 8,041 & 9,242 & 10,695 \\
\hline
\end{tabular}

Note: " $m$ " denotes an embedding dimension. Based on 20,000 replications.

\section{Quantiles of the slope coefficients $\beta_{m}$ for a sample size of 2500 observations}

\begin{tabular}{cccccccccc}
\hline Quantile & $\beta_{2}$ & $\beta_{3}$ & $\beta_{4}$ & $\beta_{5}$ & $\beta_{6}$ & $\beta_{7}$ & $\beta_{8}$ & $\beta_{9}$ & $\beta_{10}$ \\
\hline $0,5 \%$ & 1,889 & 2,826 & 3,745 & 4,625 & 5,418 & 6,183 & 6,897 & 7,544 & 8,121 \\
\hline $1,0 \%$ & 1,890 & 2,828 & 3,751 & 4,638 & 5,443 & 6,221 & 6,940 & 7,618 & 8,212 \\
\hline $2,5 \%$ & 1,892 & 2,832 & 3,759 & 4,656 & 5,483 & 6,269 & 7,006 & 7,698 & 8,331 \\
\hline $5,0 \%$ & 1,894 & 2,836 & 3,767 & 4,671 & 5,513 & 6,309 & 7,067 & 7,775 & 8,436 \\
\hline & & & & & & & & & \\
\hline $95,0 \%$ & 1,909 & 2,868 & 3,840 & 4,842 & 5,819 & 6,737 & 7,655 & 8,590 & 9,539 \\
\hline $97,5 \%$ & 1,910 & 2,871 & 3,846 & 4,856 & 5,847 & 6,779 & 7,711 & 8,666 & 9,657 \\
\hline $99,0 \%$ & 1,911 & 2,874 & 3,855 & 4,878 & 5,881 & 6,826 & 7,782 & 8,755 & 9,786 \\
\hline $99,5 \%$ & 1,912 & 2,876 & 3,859 & 4,892 & 5,898 & 6,857 & 7,825 & 8,818 & 9,880 \\
\hline
\end{tabular}

Note: " $m$ " denotes an embedding dimension. Based on 20,000 replications. 
Table 3

Quantiles of the slope coefficients $\beta_{m}$ for $\mathcal{E}$-range $(0.50 \sigma-1.50 \sigma)$

\section{A. Quantiles of the slope coefficients $\beta_{m}$ for a sample size of 500 observations}

\begin{tabular}{cccccccccc}
\hline Quantile & $\beta_{2}$ & $\beta_{3}$ & $\beta_{4}$ & $\beta_{5}$ & $\beta_{6}$ & $\beta_{7}$ & $\beta_{8}$ & $\beta_{9}$ & $\beta_{10}$ \\
\hline $0,5 \%$ & 1,678 & 2,503 & 3,310 & 4,093 & 4,831 & 5,447 & 6,011 & 6,489 & 6,959 \\
\hline $1,0 \%$ & 1,686 & 2,517 & 3,332 & 4,124 & 4,876 & 5,506 & 6,072 & 6,592 & 7,086 \\
\hline $2,5 \%$ & 1,696 & 2,534 & 3,360 & 4,163 & 4,931 & 5,581 & 6,164 & 6,717 & 7,228 \\
\hline $5,0 \%$ & 1,704 & 2,548 & 3,382 & 4,195 & 4,979 & 5,642 & 6,245 & 6,822 & 7,361 \\
\hline & & & & & & & & & \\
\hline $95,0 \%$ & 1,766 & 2,659 & 3,566 & 4,498 & 5,430 & 6,220 & 7,003 & 7,788 & 8,577 \\
\hline $97,5 \%$ & 1,770 & 2,667 & 3,581 & 4,525 & 5,467 & 6,274 & 7,075 & 7,878 & 8,699 \\
\hline $99,0 \%$ & 1,774 & 2,676 & 3,598 & 4,560 & 5,511 & 6,340 & 7,153 & 7,984 & 8,835 \\
\hline $99,5 \%$ & 1,777 & 2,682 & 3,609 & 4,583 & 5,543 & 6,387 & 7,219 & 8,061 & 8,936 \\
\hline
\end{tabular}

Note: " $m$ " denotes an embedding dimension. Based on 20,000 replications.

\section{B. Quantiles of the slope coefficients $\beta_{m}$ for a sample size of 1000 observations}

\begin{tabular}{cccccccccc}
\hline Quantile & $\beta_{2}$ & $\beta_{3}$ & $\beta_{4}$ & $\beta_{5}$ & $\beta_{6}$ & $\beta_{7}$ & $\beta_{8}$ & $\beta_{9}$ & $\beta_{10}$ \\
\hline $0,5 \%$ & 1,698 & 2,540 & 3,372 & 4,189 & 4,987 & 5,736 & 6,391 & 6,992 & 7,543 \\
\hline $1,0 \%$ & 1,703 & 2,548 & 3,386 & 4,209 & 5,011 & 5,770 & 6,438 & 7,041 & 7,610 \\
\hline $2,5 \%$ & 1,709 & 2,559 & 3,402 & 4,233 & 5,047 & 5,821 & 6,501 & 7,120 & 7,709 \\
\hline $5,0 \%$ & 1,715 & 2,567 & 3,415 & 4,253 & 5,076 & 5,868 & 6,555 & 7,186 & 7,792 \\
\hline & & & & & & & & & \\
\hline $95,0 \%$ & 1,756 & 2,639 & 3,528 & 4,428 & 5,351 & 6,278 & 7,063 & 7,826 & 8,594 \\
\hline $97,5 \%$ & 1,759 & 2,644 & 3,537 & 4,443 & 5,378 & 6,314 & 7,107 & 7,893 & 8,672 \\
\hline $99,0 \%$ & 1,762 & 2,649 & 3,546 & 4,460 & 5,406 & 6,355 & 7,156 & 7,964 & 8,758 \\
\hline $99,5 \%$ & 1,764 & 2,653 & 3,552 & 4,471 & 5,426 & 6,378 & 7,193 & 8,003 & 8,813 \\
\hline
\end{tabular}

Note: " $m$ " denotes an embedding dimension. Based on 20,000 replications.

\section{Quantiles of the slope coefficients $\beta_{m}$ for a sample size of 2500 observations}

\begin{tabular}{cccccccccc}
\hline Quantile & $\beta_{2}$ & $\beta_{3}$ & $\beta_{4}$ & $\beta_{5}$ & $\beta_{6}$ & $\beta_{7}$ & $\beta_{8}$ & $\beta_{9}$ & $\beta_{10}$ \\
\hline $0,5 \%$ & 1,715 & 2,568 & 3,418 & 4,262 & 5,095 & 5,914 & 6,702 & 7,416 & 8,045 \\
\hline $1,0 \%$ & 1,717 & 2,572 & 3,423 & 4,270 & 5,108 & 5,935 & 6,728 & 7,448 & 8,091 \\
\hline $2,5 \%$ & 1,721 & 2,578 & 3,433 & 4,283 & 5,127 & 5,958 & 6,763 & 7,498 & 8,156 \\
\hline $5,0 \%$ & 1,724 & 2,583 & 3,440 & 4,294 & 5,142 & 5,978 & 6,793 & 7,537 & 8,203 \\
\hline & & & & & & & & & \\
\hline $95,0 \%$ & 1,748 & 2,625 & 3,504 & 4,387 & 5,277 & 6,181 & 7,117 & 7,938 & 8,696 \\
\hline $97,5 \%$ & 1,750 & 2,628 & 3,509 & 4,394 & 5,290 & 6,200 & 7,151 & 7,974 & 8,742 \\
\hline $99,0 \%$ & 1,752 & 2,632 & 3,515 & 4,403 & 5,303 & 6,222 & 7,188 & 8,014 & 8,797 \\
\hline $99,5 \%$ & 1,754 & 2,634 & 3,518 & 4,409 & 5,313 & 6,237 & 7,221 & 8,048 & 8,837 \\
\hline
\end{tabular}

Note: " $m$ " denotes an embedding dimension. Based on 20,000 replications. 
Table 4

Quantiles of the slope coefficients $\beta_{m}$ for $\mathcal{E}$-range $(0.25 \sigma-2.00 \sigma)$

\section{A. Quantiles of the slope coefficients $\beta_{m}$ for a sample size of 500 observations}

\begin{tabular}{cccccccccc}
\hline Quantile & $\beta_{2}$ & $\beta_{3}$ & $\beta_{4}$ & $\beta_{5}$ & $\beta_{6}$ & $\beta_{7}$ & $\beta_{8}$ & $\beta_{9}$ & $\beta_{10}$ \\
\hline $0,5 \%$ & 1,720 & 2,561 & 3,369 & 4,024 & 4,624 & 5,158 & 5,677 & 6,155 & 6,600 \\
\hline $1,0 \%$ & 1,726 & 2,572 & 3,387 & 4,053 & 4,655 & 5,208 & 5,728 & 6,209 & 6,679 \\
\hline $2,5 \%$ & 1,734 & 2,588 & 3,412 & 4,086 & 4,701 & 5,271 & 5,800 & 6,302 & 6,781 \\
\hline $5,0 \%$ & 1,741 & 2,599 & 3,433 & 4,110 & 4,734 & 5,319 & 5,860 & 6,378 & 6,864 \\
\hline & & & & & & & & & \\
\hline $95,0 \%$ & 1,794 & 2,706 & 3,612 & 4,360 & 5,066 & 5,742 & 6,398 & 7,029 & 7,649 \\
\hline $97,5 \%$ & 1,798 & 2,715 & 3,629 & 4,381 & 5,095 & 5,782 & 6,444 & 7,080 & 7,714 \\
\hline $99,0 \%$ & 1,802 & 2,725 & 3,646 & 4,404 & 5,127 & 5,823 & 6,493 & 7,140 & 7,783 \\
\hline $99,5 \%$ & 1,804 & 2,733 & 3,660 & 4,420 & 5,152 & 5,856 & 6,523 & 7,185 & 7,834 \\
\hline
\end{tabular}

Note: " $m$ " denotes an embedding dimension. Based on 20,000 replications.

\section{B. Quantiles of the slope coefficients $\beta_{m}$ for a sample size of 1000 observations}

\begin{tabular}{cccccccccc}
\hline Quantile & $\beta_{2}$ & $\beta_{3}$ & $\beta_{4}$ & $\beta_{5}$ & $\beta_{6}$ & $\beta_{7}$ & $\beta_{8}$ & $\beta_{9}$ & $\beta_{10}$ \\
\hline $0,5 \%$ & 1,737 & 2,597 & 3,437 & 4,217 & 4,876 & 5,478 & 6,056 & 6,596 & 7,099 \\
\hline $1,0 \%$ & 1,740 & 2,603 & 3,449 & 4,233 & 4,897 & 5,502 & 6,088 & 6,634 & 7,150 \\
\hline $2,5 \%$ & 1,746 & 2,612 & 3,465 & 4,256 & 4,924 & 5,546 & 6,135 & 6,695 & 7,219 \\
\hline $5,0 \%$ & 1,750 & 2,619 & 3,477 & 4,274 & 4,948 & 5,580 & 6,176 & 6,743 & 7,278 \\
\hline & & & & & & & & & \\
\hline $95,0 \%$ & 1,785 & 2,684 & 3,598 & 4,448 & 5,179 & 5,877 & 6,547 & 7,196 & 7,827 \\
\hline $97,5 \%$ & 1,787 & 2,689 & 3,609 & 4,465 & 5,200 & 5,903 & 6,578 & 7,238 & 7,875 \\
\hline $99,0 \%$ & 1,790 & 2,695 & 3,623 & 4,483 & 5,222 & 5,932 & 6,612 & 7,283 & 7,926 \\
\hline $99,5 \%$ & 1,792 & 2,698 & 3,630 & 4,494 & 5,238 & 5,952 & 6,635 & 7,313 & 7,961 \\
\hline
\end{tabular}

Note: " $m$ " denotes an embedding dimension. Based on 20,000 replications.

\section{Quantiles of the slope coefficients $\beta_{m}$ for a sample size of 2500 observations}

\begin{tabular}{cccccccccc}
\hline Quantile & $\beta_{2}$ & $\beta_{3}$ & $\beta_{4}$ & $\beta_{5}$ & $\beta_{6}$ & $\beta_{7}$ & $\beta_{8}$ & $\beta_{9}$ & $\beta_{10}$ \\
\hline $0,5 \%$ & 1,750 & 2,622 & 3,487 & 4,336 & 5,110 & 5,790 & 6,425 & 7,025 & 7,594 \\
\hline $1,0 \%$ & 1,752 & 2,625 & 3,492 & 4,344 & 5,125 & 5,804 & 6,447 & 7,046 & 7,627 \\
\hline $2,5 \%$ & 1,755 & 2,630 & 3,500 & 4,356 & 5,144 & 5,826 & 6,475 & 7,085 & 7,668 \\
\hline $5,0 \%$ & 1,758 & 2,634 & 3,506 & 4,366 & 5,159 & 5,844 & 6,497 & 7,113 & 7,706 \\
\hline & & & & & & & & & \\
\hline $95,0 \%$ & 1,778 & 2,670 & 3,567 & 4,477 & 5,309 & 6,034 & 6,736 & 7,399 & 8,055 \\
\hline $97,5 \%$ & 1,780 & 2,673 & 3,572 & 4,487 & 5,322 & 6,052 & 6,756 & 7,423 & 8,090 \\
\hline $99,0 \%$ & 1,781 & 2,676 & 3,577 & 4,499 & 5,339 & 6,073 & 6,779 & 7,454 & 8,127 \\
\hline $99,5 \%$ & 1,783 & 2,678 & 3,581 & 4,507 & 5,351 & 6,090 & 6,797 & 7,479 & 8,153 \\
\hline Note: "m" denote
\end{tabular}

Note: " $m$ " denotes an embedding dimension. Based on 20,000 replications. 


\section{Table 5}

\section{Sensitivity of critical values with respect to $\mathcal{E}$-range choice}

\section{A. The sample size $\mathbf{T}=\mathbf{5 0 0}$}

\begin{tabular}{l|ccccccccc}
\hline Epsilon ranges & $\beta_{2}$ & $\beta_{3}$ & $\beta_{4}$ & $\beta_{5}$ & $\beta_{6}$ & $\beta_{7}$ & $\beta_{8}$ & $\beta_{9}$ & $\beta_{10}$ \\
\hline$(0.25 \sigma-1.00 \sigma)$ vs $(0.50 \sigma-1.50 \sigma)$ & 0,169 & 0,233 & 0,250 & 0,190 & 0,105 & 0,048 & $-0,072$ & $-0,363$ & $-1,043$ \\
$(0.25 \sigma-1.00 \sigma)$ vs $(0.50 \sigma-1.50 \sigma)$ & 0,163 & 0,269 & 0,406 & 0,432 & 0,498 & 0,743 & 1,127 & 1,782 & 3,298 \\
\hline$(0.50 \sigma-1.50 \sigma)$ vs $(0.25 \sigma-2.00 \sigma)$ & $-0,038$ & $-0,054$ & $-0,052$ & 0,077 & 0,230 & 0,310 & 0,364 & 0,415 & 0,447 \\
$(0.50 \sigma-1.50 \sigma)$ vs $(0.25 \sigma-2.00 \sigma)$ & $-0,028$ & $-0,048$ & $-0,048$ & 0,144 & 0,372 & 0,492 & 0,631 & 0,798 & 0,985 \\
\hline$(0.25 \sigma-1.00 \sigma)$ vs $(0.25 \sigma-2.00 \sigma)$ & 0,131 & 0,179 & 0,198 & 0,267 & 0,335 & 0,358 & 0,292 & 0,052 & $-0,596$ \\
$(0.25 \sigma-1.00 \sigma)$ vs $(0.25 \sigma-2.00 \sigma)$ & 0,135 & 0,221 & 0,358 & 0,576 & 0,870 & 1,235 & 1,758 & 2,580 & 4,283 \\
\hline
\end{tabular}

\section{B. The sample size $T=1000$}

\begin{tabular}{l|ccccccccc}
\hline Epsilon ranges & $\beta_{2}$ & $\beta_{3}$ & $\beta_{4}$ & $\beta_{5}$ & $\beta_{6}$ & $\beta_{7}$ & $\beta_{8}$ & $\beta_{9}$ & $\beta_{10}$ \\
\hline$(0.25 \sigma-1.00 \sigma)$ vs $(0.50 \sigma-1.50 \sigma)$ & 0,173 & 0,249 & 0,299 & 0,288 & 0,232 & 0,163 & 0,119 & 0,029 & $-0,130$ \\
$(0.25 \sigma-1.00 \sigma)$ vs $(0.50 \sigma-1.50 \sigma)$ & 0,159 & 0,251 & 0,374 & 0,479 & 0,492 & 0,520 & 0,742 & 1,024 & 1,476 \\
\hline$(0.50 \sigma-1.50 \sigma)$ vs $(0.25 \sigma-2.00 \sigma)$ & $-0,037$ & $-0,053$ & $-0,063$ & $-0,023$ & 0,123 & 0,275 & 0,366 & 0,425 & 0,490 \\
$(0.50 \sigma-1.50 \sigma)$ vs $(0.25 \sigma-2.00 \sigma)$ & $-0,028$ & $-0,045$ & $-0,072$ & $-0,022$ & 0,178 & 0,411 & 0,529 & 0,655 & 0,797 \\
\hline$(0.25 \sigma-1.00 \sigma)$ vs $(0.25 \sigma-2.00 \sigma)$ & 0,136 & 0,196 & 0,236 & 0,265 & 0,355 & 0,438 & 0,485 & 0,454 & 0,360 \\
$(0.25 \sigma-1.00 \sigma)$ vs $(0.25 \sigma-2.00 \sigma)$ & 0,131 & 0,206 & 0,302 & 0,457 & 0,670 & 0,931 & 1,271 & 1,679 & 2,273 \\
\hline
\end{tabular}

\section{The sample size $T=2500$}

\begin{tabular}{l|ccccccccc}
\hline Epsilon ranges & $\beta_{2}$ & $\beta_{3}$ & $\beta_{4}$ & $\beta_{5}$ & $\beta_{6}$ & $\beta_{7}$ & $\beta_{8}$ & $\beta_{9}$ & $\beta_{10}$ \\
\hline$(0.25 \sigma-1.00 \sigma)$ vs $(0.50 \sigma-1.50 \sigma)$ & 0,171 & 0,254 & 0,326 & 0,373 & 0,356 & 0,311 & 0,243 & 0,200 & 0,175 \\
$(0.25 \sigma-1.00 \sigma)$ vs $(0.50 \sigma-1.50 \sigma)$ & 0,160 & 0,243 & 0,337 & 0,462 & 0,557 & 0,579 & 0,560 & 0,692 & 0,915 \\
\hline$(0.50 \sigma-1.50 \sigma)$ vs $(0.25 \sigma-2.00 \sigma)$ & $-0,034$ & $-0,052$ & $-0,067$ & $-0,073$ & $-0,017$ & 0,132 & 0,288 & 0,413 & 0,488 \\
$(0.50 \sigma-1.50 \sigma)$ vs $(0.25 \sigma-2.00 \sigma)$ & $-0,030$ & $-0,045$ & $-0,063$ & $-0,093$ & $-0,032$ & 0,148 & 0,395 & 0,551 & 0,652 \\
\hline$(0.25 \sigma-1.00 \sigma)$ vs $(0.25 \sigma-2.00 \sigma)$ & 0,137 & 0,202 & 0,259 & 0,300 & 0,339 & 0,443 & 0,531 & 0,613 & 0,663 \\
$(0.25 \sigma-1.00 \sigma)$ vs $(0.25 \sigma-2.00 \sigma)$ & 0,130 & 0,198 & 0,274 & 0,369 & 0,525 & 0,727 & 0,955 & 1,243 & 1,567 \\
\hline
\end{tabular}

Note: The entries are differences between critical values of two different ranges; for each interval the differences are computed for $2.5 \%$ quantile (the first row) and $97.5 \%$ quantile (the second row). 
Table 6

Computed Kočenda test statistics for five processes taken from Barnett et al. (1997)

\begin{tabular}{|c|c|c|c|c|c|c|c|c|}
\hline & \multicolumn{3}{|c|}{ The sample size $\mathrm{T}=380$} & \multicolumn{4}{|c|}{ The sample size $T=2000$} \\
\hline & & $(0.25 \sigma-1.00 \sigma)$ & $(0.50 \sigma-1.50 \sigma)$ & $(0.25 \sigma-2.00 \sigma)$ & $(0.25 \sigma-1.00 \sigma)$ & $(0.50 \sigma-1.5$ & & $(0.25 \sigma-2.00 \sigma$ \\
\hline \multirow[t]{9}{*}{ FEIG } & $\overline{\beta_{2}}$ & $0,627^{a}$ & $0,652^{\text {a }}$ & $0,602^{a}$ & $0,608^{a}$ & 0,647 & & $0,587^{a}$ \\
\hline & $\beta_{3}$ & $0,629^{a}$ & $0,736^{a}$ & $0,590^{a}$ & $0,606^{a}$ & 0,733 & & $0,571^{a}$ \\
\hline & $\beta_{4}$ & $0,634^{a}$ & $0,836^{a}$ & $0,634^{a}$ & $0,604^{a}$ & 0,832 & & $0,611^{a}$ \\
\hline & $\beta_{5}$ & $0,609^{a}$ & $0,873^{a}$ & $0,653^{a}$ & $0,573^{a}$ & 0,863 & & $0,627^{a}$ \\
\hline & $\beta_{6}$ & $\overline{0,579^{a}}$ & $0,913^{a}$ & $0,673^{a}$ & $0,538^{a}$ & 0,897 & & $0,643^{a}$ \\
\hline & $\beta_{7}$ & $0,584^{a}$ & $0,913^{a}$ & $0,691^{a}$ & $0,544^{a}$ & 0,894 & & $0,660^{a}$ \\
\hline & $\beta_{8}$ & $0,589^{a}$ & $0,912^{a}$ & $0,710^{a}$ & $0,549^{a}$ & 0,890 & & $0,679^{a}$ \\
\hline & $\beta_{9}$ & $0,614^{a}$ & $0,914^{a}$ & $0,728^{a}$ & $0,577^{a}$ & 0,889 & & $0,696^{a}$ \\
\hline & $\beta_{10}$ & $0,641 \mathrm{a}$ & 0,915 a & $0,747 a$ & 0,605 a & 0,887 & & 0,714 a \\
\hline \multirow[t]{9}{*}{ GARCH } & $\overline{\beta_{2}}$ & $1,840^{\mathrm{a}}$ & $1,685^{b}$ & $1,709^{a}$ & 1,894 & 1,712 & & 1,749 a \\
\hline & $\beta_{3}$ & 2,793 & $2,504^{b}$ & $2,565^{b}$ & 2,838 & 2,541 & & $2,607^{a}$ \\
\hline & $\beta_{4}$ & 3,673 & $3,318^{b}$ & $3,359^{a}$ & $3,754^{c}$ & 3,362 & & $3,446^{a}$ \\
\hline & $\beta_{5}$ & 4,731 & $4,174^{d}$ & $4,065^{c}$ & $4,621^{a}$ & 4,174 & & $4,254^{a}$ \\
\hline & $\beta_{6}$ & 5,650 & 5,027 & $4,596^{a}$ & $5,451^{c}$ & 4,989 & & $5,018^{a}$ \\
\hline & $\beta_{7}$ & 6,091 & $5,449^{b}$ & $5,020^{a}$ & 6,318 & 5,741 & & $5,652^{a}$ \\
\hline & $\beta_{8}$ & 6,505 & $5,954^{a}$ & $5,520^{a}$ & $6,983^{c}$ & 6,511 & & $6,193^{a}$ \\
\hline & $\beta_{9}$ & 7,179 & $6,488^{a}$ & $5,992^{a}$ & $7,764^{d}$ & 7,323 & & $6,764^{a}$ \\
\hline & $\beta_{10}$ & 8,835 & $7,110^{c}$ & 6,416 a & $8,308 \mathrm{c}$ & 7,887 & & $7,288^{a}$ \\
\hline \multirow[t]{9}{*}{$\overline{\text { NLMA }}$} & $\beta_{2}$ & 1,872 & $1,640^{a}$ & $1,705^{a}$ & $1,877^{a}$ & 1,679 & & $1,720^{a}$ \\
\hline & $\beta_{3}$ & 2,795 & $2,418^{a}$ & $2,529^{a}$ & $2,794^{a}$ & 2,470 & & $2,542^{a}$ \\
\hline & $\beta_{4}$ & 3,664 & $3,214^{a}$ & $3,296^{a}$ & $3,715^{a}$ & 3,247 & & $3,361^{a}$ \\
\hline & $\beta_{5}$ & $4,345^{c}$ & $3,941^{a}$ & $3,862^{a}$ & $4,571^{a}$ & 3,999 & & $4,137^{a}$ \\
\hline & $\beta_{6}$ & $4,975^{c}$ & $4,699^{a}$ & $4,407^{a}$ & 5,442 b & 4,758 & & $4,904^{a}$ \\
\hline & $\beta_{7}$ & 5,791 & $5,409^{a}$ & $4,993^{a}$ & $6,126^{a}$ & 5,498 & & $5,417^{a}$ \\
\hline & $\beta_{8}$ & 6,918 & $6,129^{c}$ & $5,579^{a}$ & $6,742^{a}$ & 6,229 & & $5,966^{a}$ \\
\hline & $\beta_{9}$ & 7,974 & $6,723^{d}$ & $5,994^{a}$ & $7,365^{a}$ & 6,944 & & $6,495^{a}$ \\
\hline & $\beta_{10}$ & 8,400 & $7,210^{c}$ & 6,377 a & 7,988 a & 7,573 & & 7,035 a \\
\hline \multirow[t]{9}{*}{$\overline{\mathrm{ARCH}}$} & $\overline{\beta_{2}}$ & $1,799^{a}$ & $1,609^{a}$ & $1,653^{a}$ & $1,852 \mathrm{a}$ & 1,628 & & 1,679 a \\
\hline & $\beta_{3}$ & $2,710^{a}$ & $2,370^{a}$ & $2,462^{a}$ & $2,766^{a}$ & 2,406 & & $2,494^{a}$ \\
\hline & $\beta_{4}$ & $3,549 \mathrm{~b}$ & $3,181^{a}$ & $3,252^{a}$ & $3,663^{a}$ & 3,186 & & $3,301^{a}$ \\
\hline & $\beta_{5}$ & $4,362^{d}$ & $3,994^{a}$ & $3,892^{a}$ & $4,534^{a}$ & 3,961 & & $4,092^{a}$ \\
\hline & $\beta_{6}$ & 5,141 & $4,758^{a}$ & $4,426^{a}$ & $5,335^{a}$ & $4,741^{2}$ & & $4,848^{a}$ \\
\hline & $\beta_{7}$ & 5,816 & $5,423^{a}$ & $4,976^{a}$ & $6,025^{a}$ & 5,495 & & $5,444^{a}$ \\
\hline & $\beta_{8}$ & 6,643 & $6,010^{a}$ & $5,411^{a}$ & $6,747^{a}$ & 6,254 & & $5,980^{a}$ \\
\hline & $\beta_{9}$ & 7,285 & $6,538^{b}$ & $5,920^{a}$ & $7,409^{a}$ & 7,006 & & $6,538^{a}$ \\
\hline & $\beta_{10}$ & 7,076 & $7,104^{c}$ & 6,365 a & $8,125 b$ & 7,704 & & 7,117 a \\
\hline \multirow[t]{9}{*}{$\overline{\mathrm{ARMA}}$} & $\overline{\beta_{2}}$ & 1,379 a & $1,113^{a}$ & $1,213^{a}$ & $1,362^{a}$ & 1,088 & & $1,191 \mathrm{a}$ \\
\hline & $\beta_{3}$ & $1,830^{a}$ & $1,355^{a}$ & $1,544^{a}$ & $1,796^{a}$ & 1,311 & & $1,504^{a}$ \\
\hline & $\beta_{4}$ & $2,268^{a}$ & $1,592^{a}$ & $1,866^{a}$ & $2,233^{a}$ & 1,539 & & $1,820^{a}$ \\
\hline & $\beta_{5}$ & $2,704^{a}$ & $1,830^{a}$ & $2,188^{a}$ & $2,673^{a}$ & 1,771 & & $2,138^{a}$ \\
\hline & $\beta_{6}$ & $3,115^{a}$ & $2,070^{a}$ & $2,497^{a}$ & $3,104^{a}$ & 2,005 & & $2,452^{a}$ \\
\hline & $\beta_{7}$ & $3,570^{a}$ & $2,301^{a}$ & $2,828^{a}$ & $3,530^{a}$ & 2,239 & & $2,764^{a}$ \\
\hline & $\beta_{8}$ & $3,952^{a}$ & $2,528^{a}$ & $3,072^{a}$ & $3,949^{a}$ & 2,472 & & $3,072^{a}$ \\
\hline & $\beta_{9}$ & $4,223^{a}$ & $2,743^{a}$ & $3,288^{a}$ & $4,362^{a}$ & 2,702 & & $3,376^{a}$ \\
\hline & $\beta_{10}$ & 4,332 a & 2,940 a & 3,358 a & 4,783 a & 2,930 & & 3,684 a \\
\hline
\end{tabular}

Note: Superscript denotes significance at levels of (a) $1 \%$, (b) $2 \%$, (c) $5 \%$ and (d) $10 \%$. 
Table 7

Empirical power of Kočenda's test against five processes based on Barnett et al. (1997) The sample size $\mathbf{T}=\mathbf{5 0 0}$

\begin{tabular}{|c|c|c|c|c|c|c|c|c|c|c|}
\hline Process & Epsilon & $\beta_{2}$ & $\beta_{3}$ & $\beta_{4}$ & $\beta_{5}$ & $\beta_{6}$ & $\beta_{7}$ & $\beta_{8}$ & $\beta_{9}$ & $\beta_{10}$ \\
\hline \multirow[t]{3}{*}{ FEIG } & $(0.25 \sigma-1.00 \sigma)$ & $100,0 \%$ & $100,0 \%$ & $100,0 \%$ & $100,0 \%$ & $100,0 \%$ & $100,0 \%$ & $100,0 \%$ & $100,0 \%$ & $100,0 \%$ \\
\hline & $(0.50 \sigma-1.50 \sigma)$ & $100,0 \%$ & $100,0 \%$ & $100,0 \%$ & $100,0 \%$ & $100,0 \%$ & $100,0 \%$ & $100,0 \%$ & $100,0 \%$ & $100,0 \%$ \\
\hline & $(0.25 \sigma-2.00 \sigma)$ & $100,0 \%$ & $100,0 \%$ & $100,0 \%$ & $100,0 \%$ & $100,0 \%$ & $100,0 \%$ & $100,0 \%$ & $100,0 \%$ & $100,0 \%$ \\
\hline \multirow[t]{3}{*}{ GARCH } & $(0.25 \sigma-1.00 \sigma)$ & $11,1 \%$ & $10,0 \%$ & $7,0 \%$ & $6,0 \%$ & $7,4 \%$ & $6,6 \%$ & $5,1 \%$ & $2,7 \%$ & $1,4 \%$ \\
\hline & $(0.50 \sigma-1.50 \sigma)$ & $28,4 \%$ & $38,3 \%$ & $43,2 \%$ & $41,1 \%$ & $33,3 \%$ & $25,9 \%$ & $26,5 \%$ & $26,0 \%$ & $25,5 \%$ \\
\hline & $(0.25 \sigma-2.00 \sigma)$ & $28,5 \%$ & $35,3 \%$ & $31,4 \%$ & $36,7 \%$ & $43,6 \%$ & $47,9 \%$ & $49,5 \%$ & $51,6 \%$ & $52,1 \%$ \\
\hline \multirow[t]{3}{*}{$\overline{\mathrm{NLMA}}$} & $(0.25 \sigma-1.00 \sigma)$ & $28,1 \%$ & $28,8 \%$ & $17,0 \%$ & $15,7 \%$ & $16,0 \%$ & $13,4 \%$ & $9,4 \%$ & $3,7 \%$ & $0,4 \%$ \\
\hline & $(0.50 \sigma-1.50 \sigma)$ & $73,2 \%$ & $90,2 \%$ & $93,8 \%$ & $91,8 \%$ & $83,7 \%$ & $70,5 \%$ & $67,8 \%$ & $62,2 \%$ & $56,0 \%$ \\
\hline & $(0.25 \sigma-2.00 \sigma)$ & $71,2 \%$ & $85,1 \%$ & $80,7 \%$ & $88,4 \%$ & $91,9 \%$ & $91,9 \%$ & $91,3 \%$ & $90,2 \%$ & $88,9 \%$ \\
\hline \multirow[t]{3}{*}{$\overline{\mathrm{ARCH}}$} & $(0.25 \sigma-1.00 \sigma)$ & $76,7 \%$ & $60,4 \%$ & $30,8 \%$ & $19,2 \%$ & $16,9 \%$ & $12,7 \%$ & $7,1 \%$ & $3,1 \%$ & $0,3 \%$ \\
\hline & $(0.50 \sigma-1.50 \sigma)$ & $97,6 \%$ & $97,8 \%$ & $97,1 \%$ & $93,4 \%$ & $85,9 \%$ & $68,8 \%$ & $67,2 \%$ & $64,0 \%$ & $57,1 \%$ \\
\hline & $(0.25 \sigma-2.00 \sigma)$ & $97,1 \%$ & $96,7 \%$ & $90,1 \%$ & $89,0 \%$ & $91,6 \%$ & $91,4 \%$ & $90,1 \%$ & $88,9 \%$ & $86,9 \%$ \\
\hline \multirow[t]{3}{*}{$\overline{\text { ARMA }}$} & $(0.25 \sigma-1.00 \sigma)$ & $100,0 \%$ & $100,0 \%$ & $100,0 \%$ & $100,0 \%$ & $100,0 \%$ & $100,0 \%$ & $100,0 \%$ & $100,0 \%$ & $99,9 \%$ \\
\hline & $(0.50 \sigma-1.50 \sigma)$ & $100,0 \%$ & $100,0 \%$ & $100,0 \%$ & $100,0 \%$ & $100,0 \%$ & $100,0 \%$ & $100,0 \%$ & $100,0 \%$ & $100,0 \%$ \\
\hline & $(0.25 \sigma-2.00 \sigma)$ & $100,0 \%$ & $100,0 \%$ & $100,0 \%$ & $100,0 \%$ & $100,0 \%$ & $100,0 \%$ & $100,0 \%$ & $100,0 \%$ & $100,0 \%$ \\
\hline
\end{tabular}

Note: The entries are rejection rates in $\%$, computed at the $5 \%$ level.

Table 8

Empirical power of Kočenda's test against five processes based on Barnett et al. (1997)

The sample size $T=1000$

\begin{tabular}{|c|c|c|c|c|c|c|c|c|c|c|}
\hline Process & Epsilon & $\beta_{2}$ & $\beta_{3}$ & $\beta_{4}$ & $\beta_{5}$ & $\beta_{6}$ & $\beta_{7}$ & $\beta_{8}$ & $\beta_{9}$ & $\beta_{10}$ \\
\hline \multirow[t]{3}{*}{ FEIG } & $(0.250$ & $100,0 \%$ & $100,0 \%$ & $100,0 \%$ & $100,0 \%$ & $100,0 \%$ & $100,0 \%$ & $100,0 \%$ & $100,0 \%$ & $100,0 \%$ \\
\hline & $(0.50 \sigma-1.50 \sigma)$ & $100,0 \%$ & $100,0 \%$ & $100,0 \%$ & $100,0 \%$ & $100,0 \%$ & $100,0 \%$ & $100,0 \%$ & $100,0 \%$ & $100,0 \%$ \\
\hline & $(0.25 \sigma-2.00 \sigma)$ & $100,0 \%$ & $100,0 \%$ & $100,0 \%$ & $100,0 \%$ & $100,0 \%$ & $100,0 \%$ & $100,0 \%$ & $100,0 \%$ & $100,0 \%$ \\
\hline \multirow[t]{3}{*}{ GARCH } & $(0.25 \sigma-1.00 \sigma)$ & $24,3 \%$ & $21,8 \%$ & $12,3 \%$ & $7,1 \%$ & $6,5 \%$ & $8,1 \%$ & $6,7 \%$ & $5,8 \%$ & $4,1 \%$ \\
\hline & $(0.50 \sigma-1.50 \sigma)$ & $49,5 \%$ & $65,4 \%$ & $71,5 \%$ & $70,4 \%$ & $66,9 \%$ & $53,5 \%$ & $40,4 \%$ & $43,2 \%$ & $42,6 \%$ \\
\hline & $(0.25 \sigma-2.00 \sigma)$ & $50,5 \%$ & $60,6 \%$ & $57,9 \%$ & $46,2 \%$ & $60,6 \%$ & $66,7 \%$ & $71,4 \%$ & $74,8 \%$ & $75,4 \%$ \\
\hline \multirow[t]{3}{*}{$\overline{\text { NLMA }}$} & $(0.25 \sigma-1.00 \sigma)$ & $70,0 \%$ & $76,9 \%$ & $57,0 \%$ & $23,1 \%$ & $27,9 \%$ & $28,5 \%$ & $26,8 \%$ & $18,6 \%$ & $10,5 \%$ \\
\hline & $\begin{array}{l}(0.50 \sigma-1.50 \sigma) \\
\end{array}$ & $95,3 \%$ & $99,8 \%$ & $100,0 \%$ & $100,0 \%$ & $99,9 \%$ & $99,0 \%$ & $93,4 \%$ & $92,9 \%$ & $90,2 \%$ \\
\hline & $(0.25 \sigma-2.00 \sigma)$ & $95,9 \%$ & $99,4 \%$ & $99,2 \%$ & $97,6 \%$ & $98,9 \%$ & $99,8 \%$ & $99,9 \%$ & $99,9 \%$ & $100,0 \%$ \\
\hline \multirow[t]{3}{*}{$\overline{\mathrm{ARCH}}$} & $(0.25 \sigma-1.00 \sigma)$ & $99,2 \%$ & $96,3 \%$ & $79,5 \%$ & $38,2 \%$ & $29,7 \%$ & $26,6 \%$ & $21,4 \%$ & $12,4 \%$ & $6,8 \%$ \\
\hline & $(0.50 \sigma-1.50 \sigma)$ & $100,0 \%$ & $100,0 \%$ & $100,0 \%$ & $100,0 \%$ & $99,8 \%$ & $98,0 \%$ & $89,8 \%$ & $87,8 \%$ & $86,3 \%$ \\
\hline & $(0.25 \sigma-2.00 \sigma)$ & $100,0 \%$ & $100,0 \%$ & $100,0 \%$ & $98,7 \%$ & $99,1 \%$ & $99,3 \%$ & $99,6 \%$ & $99,4 \%$ & $98,7 \%$ \\
\hline \multirow[t]{3}{*}{ ARMA } & $(0.25 \sigma-1.00 \sigma)$ & $100,0 \%$ & $100,0 \%$ & $100,0 \%$ & $100,0 \%$ & $100,0 \%$ & $100,0 \%$ & $100,0 \%$ & $100,0 \%$ & $100,0 \%$ \\
\hline & $(0.50 \sigma-1.50 \sigma)$ & $100,0 \%$ & $100,0 \%$ & $100,0 \%$ & $100,0 \%$ & $100,0 \%$ & $100,0 \%$ & $100,0 \%$ & $100,0 \%$ & $100,0 \%$ \\
\hline & $(0.25 \sigma-2.00 \sigma)$ & $100,0 \%$ & $100,0 \%$ & $100,0 \%$ & $100,0 \%$ & $100,0 \%$ & $100,0 \%$ & $100,0 \%$ & $100,0 \%$ & $100,0 \%$ \\
\hline
\end{tabular}

Note: The entries are rejection rates in $\%$, computed at the $5 \%$ level. 
Table 9

Empirical power of Kočenda's test against five processes based on Barnett et al. (1997) The sample size $\mathbf{T}=\mathbf{2 5 0 0}$

\begin{tabular}{lcccccccccc}
\hline Process & Epsilon & $\beta_{2}$ & $\beta_{3}$ & $\beta_{4}$ & $\beta_{5}$ & $\beta_{6}$ & $\beta_{7}$ & $\beta_{8}$ & $\beta_{9}$ & $\beta_{10}$ \\
\hline FEIG & $(0.25 \sigma-1.00 \sigma)$ & $100,0 \%$ & $100,0 \%$ & $100,0 \%$ & $100,0 \%$ & $100,0 \%$ & $100,0 \%$ & $100,0 \%$ & $100,0 \%$ & $100,0 \%$ \\
\hline & $(0.50 \sigma-1.50 \sigma)$ & $100,0 \%$ & $100,0 \%$ & $100,0 \%$ & $100,0 \%$ & $100,0 \%$ & $100,0 \%$ & $100,0 \%$ & $100,0 \%$ & $100,0 \%$ \\
\cline { 2 - 9 } & $(0.25 \sigma-2.00 \sigma)$ & $100,0 \%$ & $100,0 \%$ & $100,0 \%$ & $100,0 \%$ & $100,0 \%$ & $100,0 \%$ & $100,0 \%$ & $100,0 \%$ & $100,0 \%$ \\
\hline GARCH & $(0.25 \sigma-1.00 \sigma)$ & $65,4 \%$ & $68,5 \%$ & $53,8 \%$ & $29,1 \%$ & $11,7 \%$ & $14,6 \%$ & $15,0 \%$ & $14,1 \%$ & $11,6 \%$ \\
\hline \multirow{2}{*}{ NLMA } & $(0.50 \sigma-1.50 \sigma)$ & $86,7 \%$ & $96,6 \%$ & $98,5 \%$ & $98,8 \%$ & $98,3 \%$ & $97,5 \%$ & $92,3 \%$ & $76,7 \%$ & $75,3 \%$ \\
\cline { 2 - 9 } & $(0.25 \sigma-2.00 \sigma)$ & $86,6 \%$ & $95,6 \%$ & $96,9 \%$ & $92,1 \%$ & $84,3 \%$ & $91,4 \%$ & $94,9 \%$ & $95,7 \%$ & $96,9 \%$ \\
\hline & $(0.25 \sigma-1.00 \sigma)$ & $99,9 \%$ & $100,0 \%$ & $99,7 \%$ & $94,6 \%$ & $51,7 \%$ & $60,9 \%$ & $57,7 \%$ & $55,1 \%$ & $42,7 \%$ \\
\hline ARCH & $(0.25 \sigma-2.00 \sigma)$ & $100,0 \%$ & $100,0 \%$ & $100,0 \%$ & $100,0 \%$ & $100,0 \%$ & $100,0 \%$ & $100,0 \%$ & $100,0 \%$ & $99,9 \%$ \\
\cline { 2 - 9 } & $(0.25 \sigma-1.00 \sigma)$ & $100,0 \%$ & $100,0 \%$ & $100,0 \%$ & $100,0 \%$ & $100,0 \%$ & $100,0 \%$ & $100,0 \%$ & $100,0 \%$ & $100,0 \%$ \\
\hline & $(0.50 \sigma-1.50 \sigma)$ & $100,0 \%$ & $100,0 \%$ & $100,0 \%$ & $98,1 \%$ & $62,7 \%$ & $53,8 \%$ & $47,3 \%$ & $41,0 \%$ & $30,8 \%$ \\
\hline ARMA & $(0.25 \sigma-2.00 \sigma)$ & $100,0 \%$ & $100,0 \%$ & $100,0 \%$ & $100,0 \%$ & $100,0 \%$ & $100,0 \%$ & $100,0 \%$ & $99,7 \%$ & $99,1 \%$ \\
\cline { 2 - 9 } & $(0.25 \sigma-1.00 \sigma)$ & $100,0 \%$ & $100,0 \%$ & $100,0 \%$ & $100,0 \%$ & $100,0 \%$ & $100,0 \%$ & $100,0 \%$ & $100,0 \%$ & $100,0 \%$ \\
\hline & $(0.50 \sigma-1.50 \sigma)$ & $100,0 \%$ & $100,0 \%$ & $100,0 \%$ & $100,0 \%$ & $100,0 \%$ & $100,0 \%$ & $100,0 \%$ & $100,0 \%$ & $100,0 \%$ \\
\hline
\end{tabular}

Note: The entries are rejection rates in $\%$, computed at the $5 \%$ level. 
Table 10

Empirical power of Kočenda's test against chaotic processes and chaotic processes with noise The sample size $\mathbf{T}=\mathbf{5 0 0}$

\begin{tabular}{|c|c|c|c|c|c|c|c|c|c|c|}
\hline ss & on & $\beta_{2}$ & $\beta_{3}$ & $\beta_{4}$ & $\beta_{5}$ & $\beta_{6}$ & $\beta_{7}$ & $\beta_{8}$ & $\beta_{9}$ & $\beta_{10}$ \\
\hline \multirow[t]{3}{*}{ Henon } & $.25 \sigma-1.00 \sigma)$ & $100,0 \%$ & $100,0 \%$ & $100,0 \%$ & $100,0 \%$ & $100,0 \%$ & $100,0 \%$ & $100,0 \%$ & $100,0 \%$ & $100,0 \%$ \\
\hline & $50 \sigma-1.50 \sigma)$ & $100,0 \%$ & $100,0 \%$ & $100,0 \%$ & $100,0 \%$ & $100,0 \%$ & $100,0 \%$ & $100,0 \%$ & $100,0 \%$ & $100,0 \%$ \\
\hline & $(0.25 \sigma-2.00 \sigma)$ & $100,0 \%$ & $100,0 \%$ & $100,0 \%$ & $100,0 \%$ & $100,0 \%$ & $100,0 \%$ & $100,0 \%$ & $100,0 \%$ & $100,0 \%$ \\
\hline \multirow[t]{3}{*}{ Lorenz } & $(0.25 \sigma-1.00 \sigma)$ & $100,0 \%$ & $100,0 \%$ & $100,0 \%$ & $100,0 \%$ & $100,0 \%$ & $100,0 \%$ & $100,0 \%$ & $100,0 \%$ & $100,0 \%$ \\
\hline & $(0.50 \sigma-1.50 \sigma)$ & $100,0 \%$ & $100,0 \%$ & $100,0 \%$ & $100,0 \%$ & $100,0 \%$ & $100,0 \%$ & $100,0 \%$ & $100,0 \%$ & $100,0 \%$ \\
\hline & $(0.25 \sigma-2.00 \sigma)$ & $100,0 \%$ & $100,0 \%$ & $100,0 \%$ & $100,0 \%$ & $100,0 \%$ & $100,0 \%$ & $100,0 \%$ & $100,0 \%$ & $100,0 \%$ \\
\hline \multirow{3}{*}{$\begin{array}{l}\text { Henon } \\
+ \text { noise }\end{array}$} & $(0.25 \sigma-1.00 \sigma)$ & $100,0 \%$ & $100,0 \%$ & $100,0 \%$ & $100,0 \%$ & $100,0 \%$ & $100,0 \%$ & $100,0 \%$ & $100,0 \%$ & $100,0 \%$ \\
\hline & $(0.50 \sigma-1.50 \sigma)$ & $100,0 \%$ & $100,0 \%$ & $100,0 \%$ & $100,0 \%$ & $100,0 \%$ & $100,0 \%$ & $100,0 \%$ & $100,0 \%$ & $100,0 \%$ \\
\hline & $(0.25 \sigma-2.00 \sigma)$ & $100,0 \%$ & $100,0 \%$ & $100,0 \%$ & $100,0 \%$ & $100,0 \%$ & $100,0 \%$ & $100,0 \%$ & $100,0 \%$ & $100,0 \%$ \\
\hline \multirow{3}{*}{$\begin{array}{l}\text { Lorenz } \\
+ \text { noise }\end{array}$} & $(0.25 \sigma-1.00 \sigma)$ & $100,0 \%$ & $100,0 \%$ & $100,0 \%$ & $100,0 \%$ & $100,0 \%$ & $100,0 \%$ & $100,0 \%$ & $100,0 \%$ & $100,0 \%$ \\
\hline & $(0.50 \sigma-1.50 \sigma)$ & $100,0 \%$ & $100,0 \%$ & $100,0 \%$ & $100,0 \%$ & $100,0 \%$ & $100,0 \%$ & $100,0 \%$ & $100,0 \%$ & $100,0 \%$ \\
\hline & $(0.25 \sigma-2.00 \sigma)$ & $100,0 \%$ & $100,0 \%$ & $100,0 \%$ & $100,0 \%$ & $100,0 \%$ & $100,0 \%$ & $100,0 \%$ & $100,0 \%$ & $100,0 \%$ \\
\hline
\end{tabular}

Note: The entries are rejection rates in \%, computed at the $5 \%$ level.

Table 11

Empirical power of Kočenda's test against chaotic processes and chaotic processes with noise The sample size $\mathrm{T}=1000$

\begin{tabular}{|c|c|c|c|c|c|c|c|c|c|c|}
\hline ess & n & $\beta_{2}$ & $\beta_{3}$ & $\beta_{4}$ & $\beta_{5}$ & $\beta_{6}$ & $\overline{\beta_{7}}$ & $\overline{\beta_{8}}$ & $\beta_{9}$ & $\overline{\beta_{10}}$ \\
\hline \multirow[t]{3}{*}{ Henon } & $(0.25 \sigma-1.00 \sigma)$ & $100,0 \%$ & $100,0 \%$ & $100,0 \%$ & $100,0 \%$ & $100,0 \%$ & $100,0 \%$ & $100,0 \%$ & $100,0 \%$ & $100,0 \%$ \\
\hline & $.50 \sigma-1.50 \sigma)$ & $100,0 \%$ & $100,0 \%$ & $100,0 \%$ & $100,0 \%$ & $100,0 \%$ & $100,0 \%$ & $100,0 \%$ & $100,0 \%$ & $100,0 \%$ \\
\hline & $(0.25 \sigma-2.00 \sigma)$ & $100,0 \%$ & $100,0 \%$ & $100,0 \%$ & $100,0 \%$ & $100,0 \%$ & $100,0 \%$ & $100,0 \%$ & $100,0 \%$ & $100,0 \%$ \\
\hline \multirow[t]{3}{*}{ Lorenz } & $(0.25 \sigma-1.00 \sigma)$ & $100,0 \%$ & $100,0 \%$ & $100,0 \%$ & $100,0 \%$ & $100,0 \%$ & $100,0 \%$ & $100,0 \%$ & $100,0 \%$ & $100,0 \%$ \\
\hline & $(0.50 \sigma-1.50 \sigma)$ & $100,0 \%$ & $100,0 \%$ & $100,0 \%$ & $100,0 \%$ & $100,0 \%$ & $100,0 \%$ & $100,0 \%$ & $100,0 \%$ & $100,0 \%$ \\
\hline & $(0.25 \sigma-2.00 \sigma)$ & $100,0 \%$ & $100,0 \%$ & $100,0 \%$ & $100,0 \%$ & $100,0 \%$ & $100,0 \%$ & $100,0 \%$ & $100,0 \%$ & $100,0 \%$ \\
\hline \multirow{3}{*}{$\begin{array}{l}\text { Henon } \\
\text { +noise }\end{array}$} & $(0.25 \sigma-1.00 \sigma)$ & $100,0 \%$ & $100,0 \%$ & $100,0 \%$ & $100,0 \%$ & $100,0 \%$ & $100,0 \%$ & $100,0 \%$ & $100,0 \%$ & $100,0 \%$ \\
\hline & $(0.50 \sigma-1.50 \sigma)$ & $100,0 \%$ & $100,0 \%$ & $100,0 \%$ & $100,0 \%$ & $100,0 \%$ & $100,0 \%$ & $100,0 \%$ & $100,0 \%$ & $100,0 \%$ \\
\hline & $(0.25 \sigma-2.00 \sigma)$ & $100,0 \%$ & $100,0 \%$ & $100,0 \%$ & $100,0 \%$ & $100,0 \%$ & $100,0 \%$ & $100,0 \%$ & $100,0 \%$ & $100,0 \%$ \\
\hline \multirow{3}{*}{$\begin{array}{l}\text { Lorenz } \\
+ \text { noise }\end{array}$} & $(0.25 \sigma-1.00 \sigma)$ & $100,0 \%$ & $100,0 \%$ & $100,0 \%$ & $100,0 \%$ & $100,0 \%$ & $100,0 \%$ & $100,0 \%$ & $100,0 \%$ & $100,0 \%$ \\
\hline & $(0.50 \sigma-1.50 \sigma)$ & $100,0 \%$ & $100,0 \%$ & $100,0 \%$ & $100,0 \%$ & $100,0 \%$ & $100,0 \%$ & $100,0 \%$ & $100,0 \%$ & $100,0 \%$ \\
\hline & $(0.25 \sigma-2.00 \sigma)$ & $100,0 \%$ & $100,0 \%$ & $100,0 \%$ & $100,0 \%$ & $100,0 \%$ & $100,0 \%$ & $100,0 \%$ & $100,0 \%$ & $100,0 \%$ \\
\hline
\end{tabular}

Note: The entries are rejection rates in \%, computed at the $5 \%$ level.

Table 12

Empirical power of Kočenda's test against chaotic processes and chaotic processes with noise The sample size $\mathrm{T}=\mathbf{2 5 0 0}$

\begin{tabular}{lcccccccccc}
\hline Process & Epsilon & $\beta_{2}$ & $\beta_{3}$ & $\beta_{4}$ & $\beta_{5}$ & $\beta_{6}$ & $\beta_{7}$ & $\beta_{8}$ & $\beta_{9}$ & $\beta_{10}$ \\
\hline Henon & $(0.25 \sigma-1.00 \sigma)$ & $100,0 \%$ & $100,0 \%$ & $100,0 \%$ & $100,0 \%$ & $100,0 \%$ & $100,0 \%$ & $100,0 \%$ & $100,0 \%$ & $100,0 \%$ \\
\hline & $(0.50 \sigma-1.50 \sigma)$ & $100,0 \%$ & $100,0 \%$ & $100,0 \%$ & $100,0 \%$ & $100,0 \%$ & $100,0 \%$ & $100,0 \%$ & $100,0 \%$ & $100,0 \%$ \\
\hline & $(0.25 \sigma-2.00 \sigma)$ & $100,0 \%$ & $100,0 \%$ & $100,0 \%$ & $100,0 \%$ & $100,0 \%$ & $100,0 \%$ & $100,0 \%$ & $100,0 \%$ & $100,0 \%$ \\
\hline Lorenz & $(0.25 \sigma-1.00 \sigma)$ & $100,0 \%$ & $100,0 \%$ & $100,0 \%$ & $100,0 \%$ & $100,0 \%$ & $100,0 \%$ & $100,0 \%$ & $100,0 \%$ & $100,0 \%$ \\
\hline \multirow{3}{*}{$\begin{array}{l}\text { Henon } \\
\text { +noise }\end{array}$} & $(0.50 \sigma-1.50 \sigma)$ & $100,0 \%$ & $100,0 \%$ & $100,0 \%$ & $100,0 \%$ & $100,0 \%$ & $100,0 \%$ & $100,0 \%$ & $100,0 \%$ & $100,0 \%$ \\
\cline { 2 - 9 } & $(0.25 \sigma-2.00 \sigma)$ & $100,0 \%$ & $100,0 \%$ & $100,0 \%$ & $100,0 \%$ & $100,0 \%$ & $100,0 \%$ & $100,0 \%$ & $100,0 \%$ & $100,0 \%$ \\
\cline { 2 - 9 } & $(0.50 \sigma-1.50 \sigma)$ & $100,0 \%$ & $100,0 \%$ & $100,0 \%$ & $100,0 \%$ & $100,0 \%$ & $100,0 \%$ & $100,0 \%$ & $100,0 \%$ & $100,0 \%$ \\
\hline Lorenz & $(0.25 \sigma-2.00 \sigma)$ & $100,0 \%$ & $100,0 \%$ & $100,0 \%$ & $100,0 \%$ & $100,0 \%$ & $100,0 \%$ & $100,0 \%$ & $100,0 \%$ & $100,0 \%$ \\
\hline +noise & $(0.25 \sigma-1.00 \sigma)$ & $100,0 \%$ & $100,0 \%$ & $100,0 \%$ & $100,0 \%$ & $100,0 \%$ & $100,0 \%$ & $100,0 \%$ & $100,0 \%$ & $100,0 \%$ \\
\cline { 2 - 9 } & $(0.25 \sigma-1.50 \sigma)$ & $100,0 \%$ & $100,0 \%$ & $100,0 \%$ & $100,0 \%$ & $100,0 \%$ & $100,0 \%$ & $100,0 \%$ & $100,0 \%$ & $100,0 \%$ \\
\hline
\end{tabular}

Note: The entries are rejection rates in $\%$, computed at the $5 \%$ level. 
Figure 1a

Relative differences of critical values with respect to $\varepsilon$-range choice

(in absolute value)

\section{A. Dispersion of $\mathbf{2 . 5 \%}$ quantile for $\mathbf{5 0 0}$ observations}

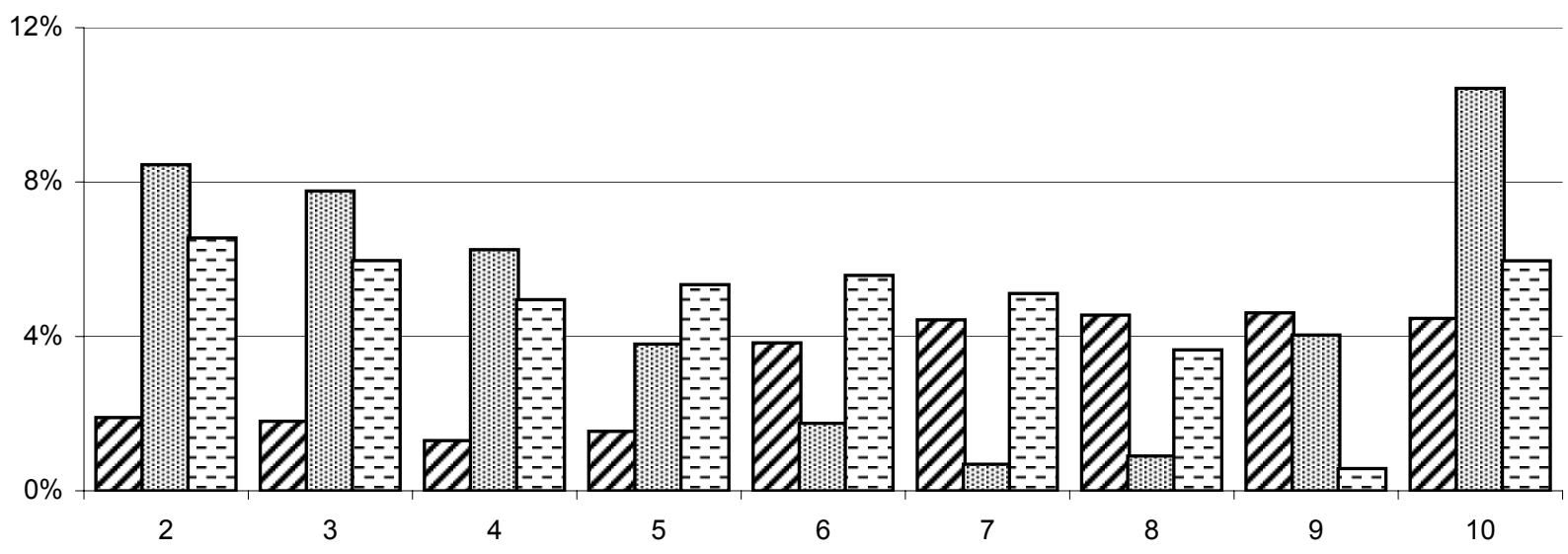

B. Dispersion of $\mathbf{2 . 5 \%}$ quantile for $\mathbf{1 0 0 0}$ observations
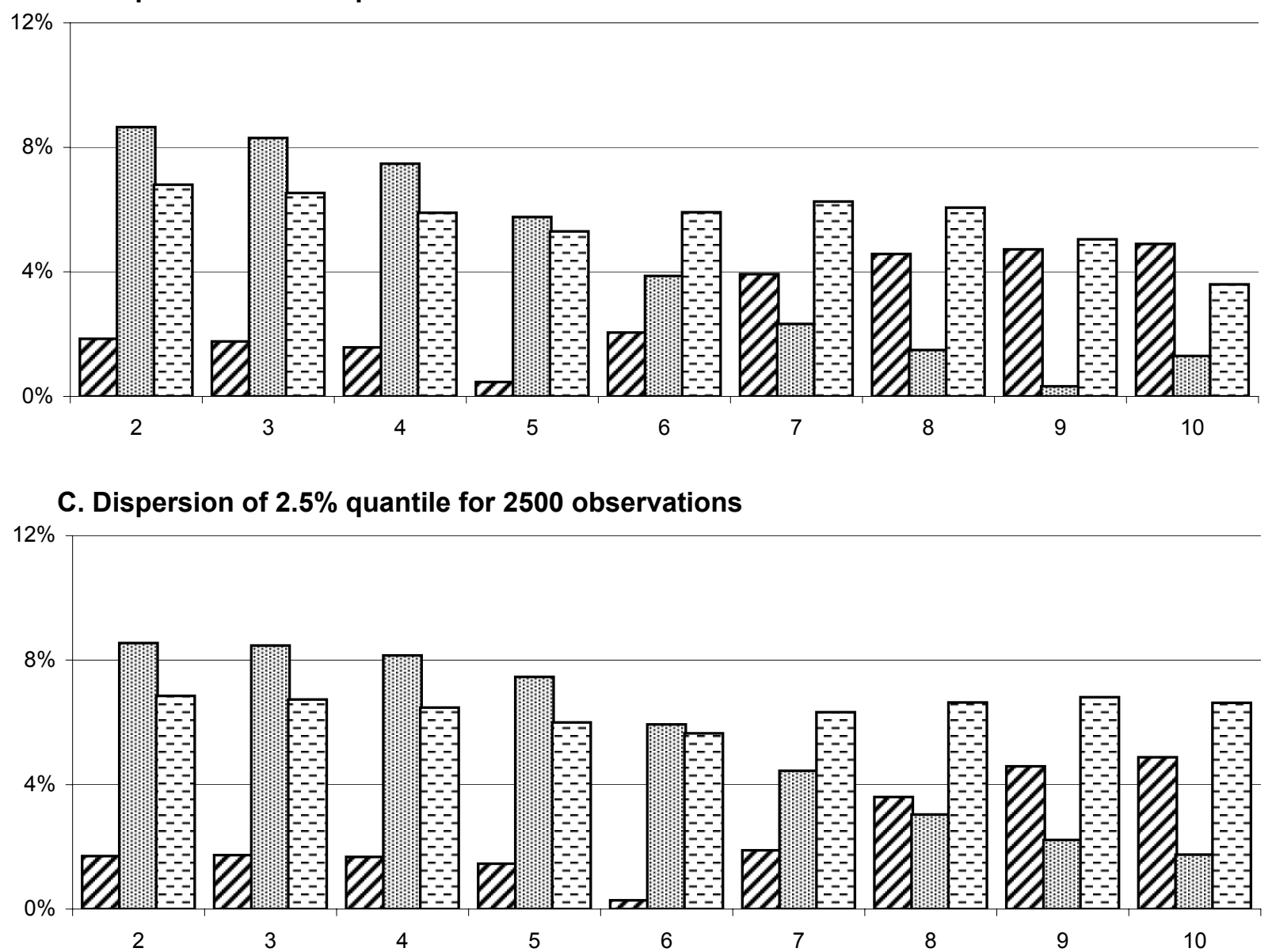

Note: The entries are relative changes of critical values; they are computed as appropriate quantile differences between two intervals over embedding dimension $m$. For better understanding we picture them in absolute values. 
Figure 1b

Relative differences of critical values with respect to $\varepsilon$-range choice

(in absolute value)

\section{A. Dispersion of $\mathbf{9 7 . 5 \%}$ quantile for $\mathbf{5 0 0}$ observations}

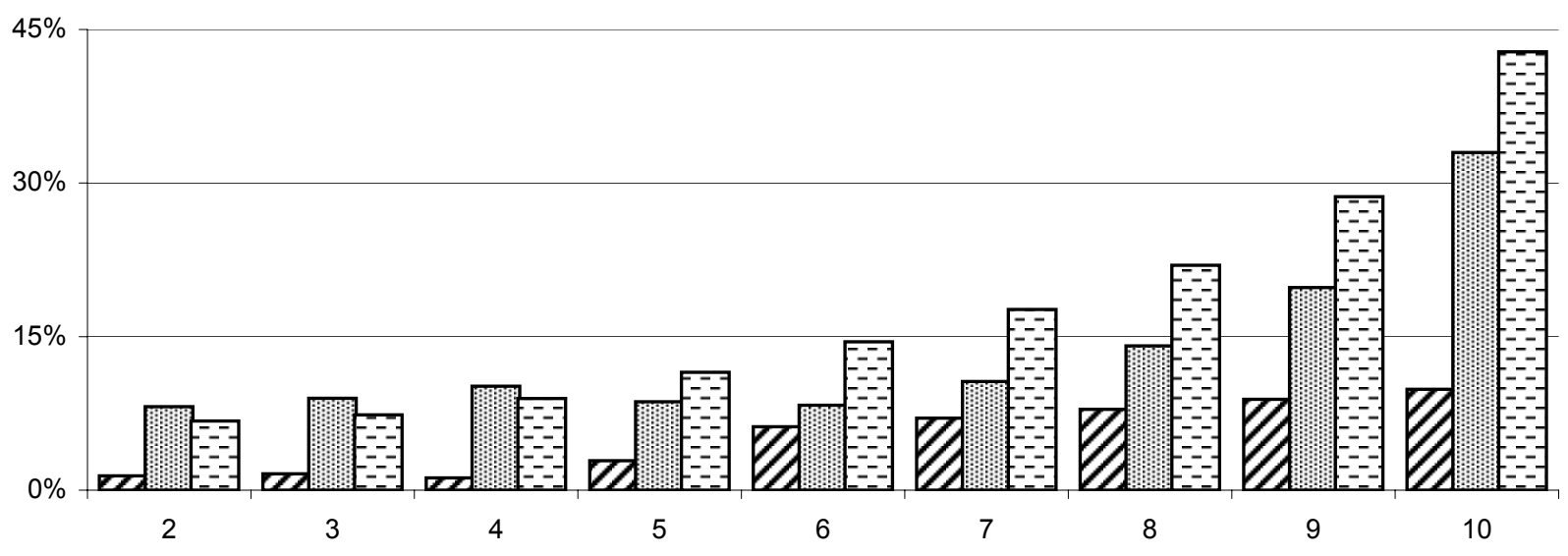

B. Dispersion of $\mathbf{9 7 . 5 \%}$ quantile for 1000 observations
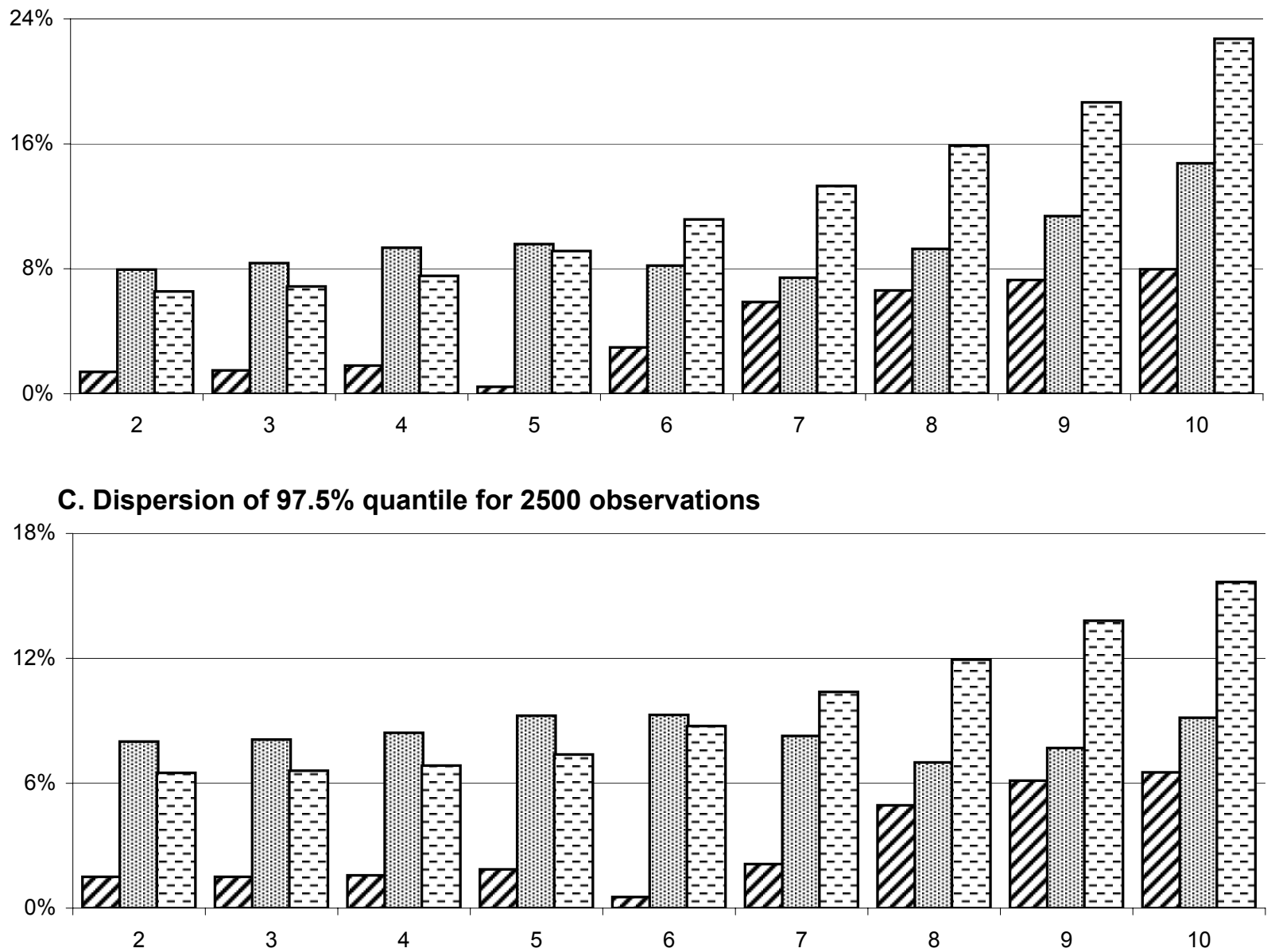

Note: The entries are relative changes of critical values; they are computed as appropriate quantile differences between two intervals over embedding dimension $m$. For better understanding we picture them in absolute values. 
Figure 2

Histograms of standardized residuals from exchange rate models

DEM/USD (BHL 91)

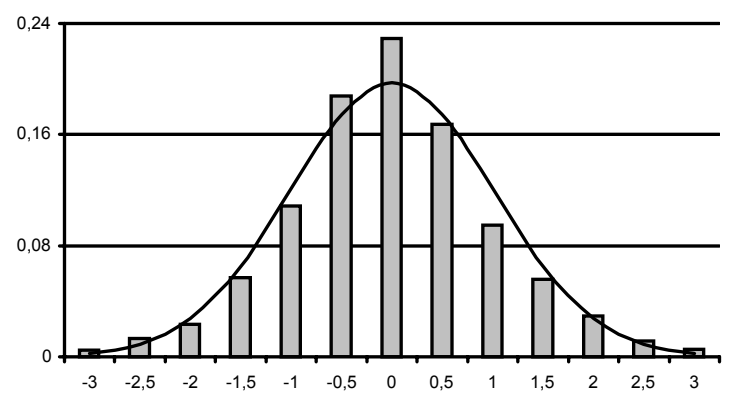

FRF/USD (KL 90)

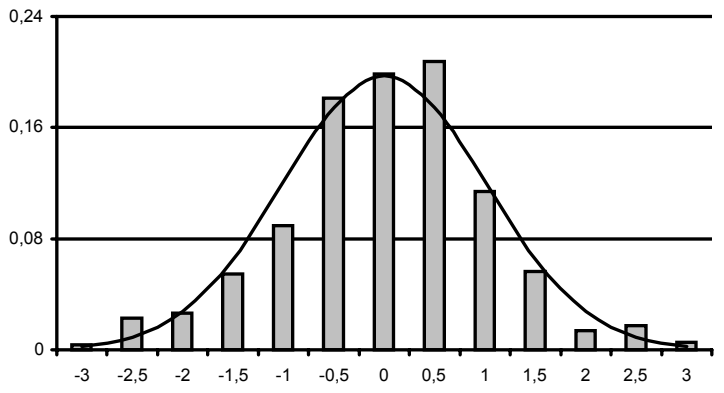

CHF/USD (KL 93)

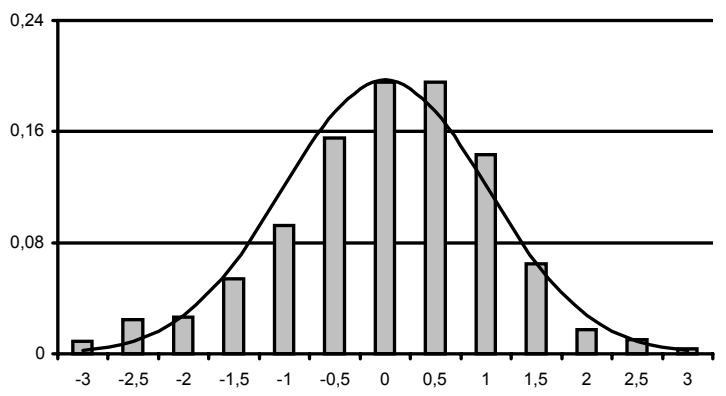

CHF/USD (BHL 91)

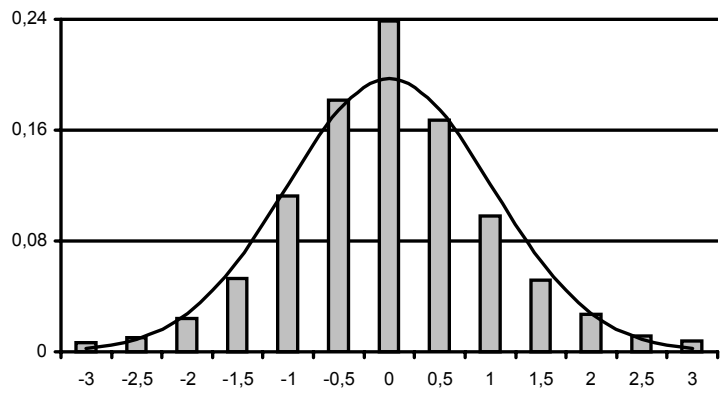

CHF/USD (KL 90)

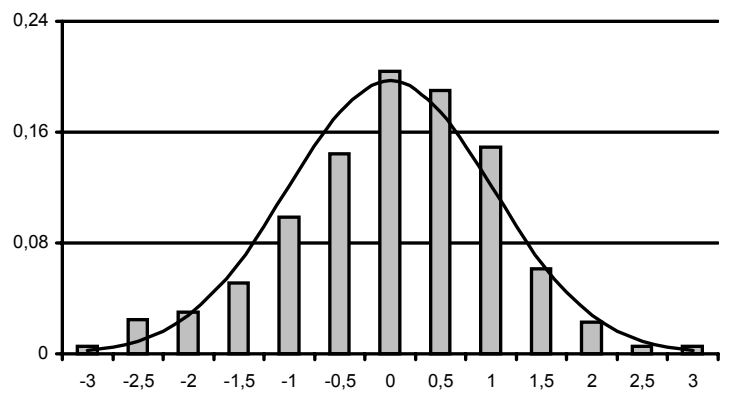

JPYIUSD (KL 93)

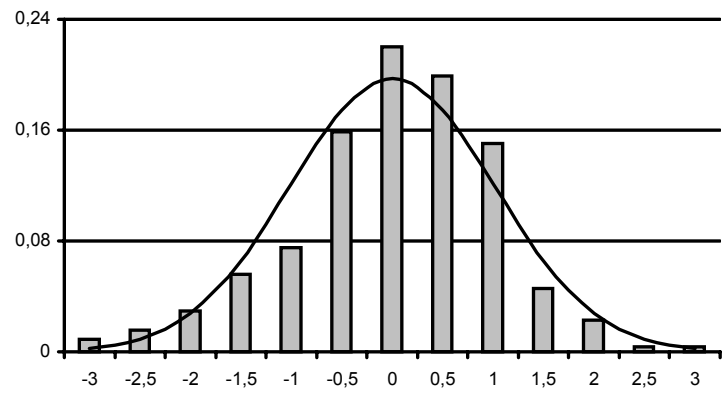

Note: BHL91, KL90 and KL93 are standardized residuals for a particular exchange rate from Brock, Hsieh and Lebaron (1991), Kugler and Lenz (1990), and Kugler and Lenz (1993) respectively. 
Figure 3

Histograms of standardized residuals from models of stock indices

S\&P500 Index

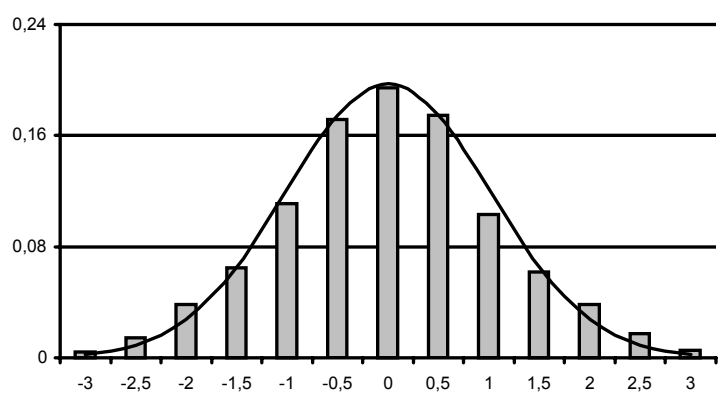

DJ Index

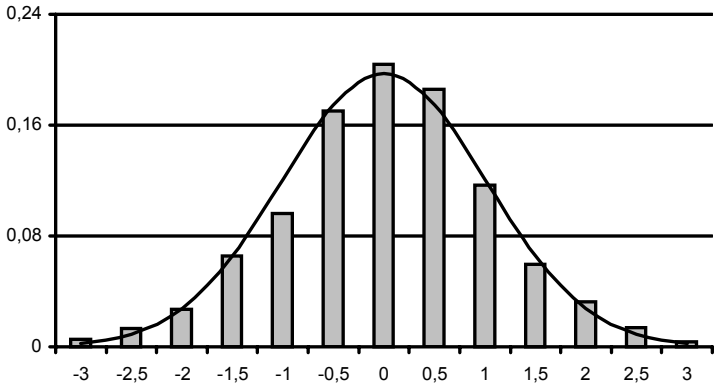

Note: S\&P500 Index and DJ Index are standardized residuals of particular stock market index from Hsieh (1991) and Engle and Patton (2001) respectively.

Figure 4

Histograms of non-linear processes based on Barnett et al. (1997)

GARCH

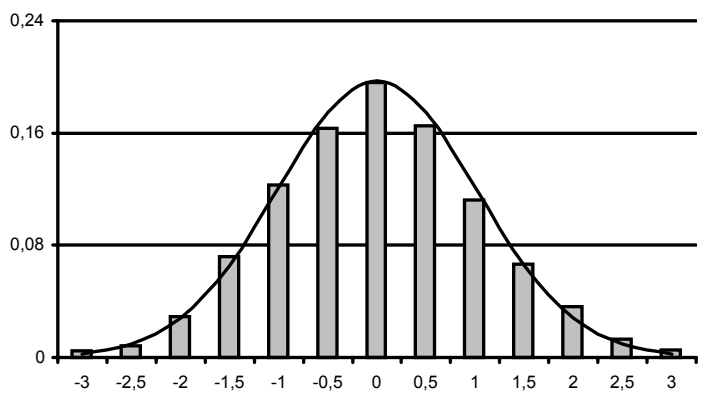

$\mathrm{ARCH}$

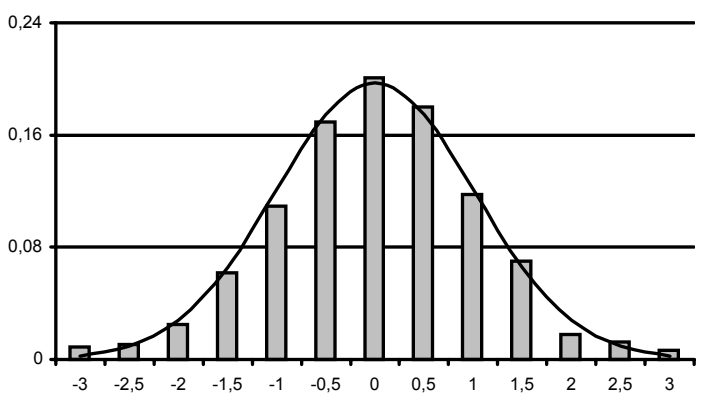

NLMA

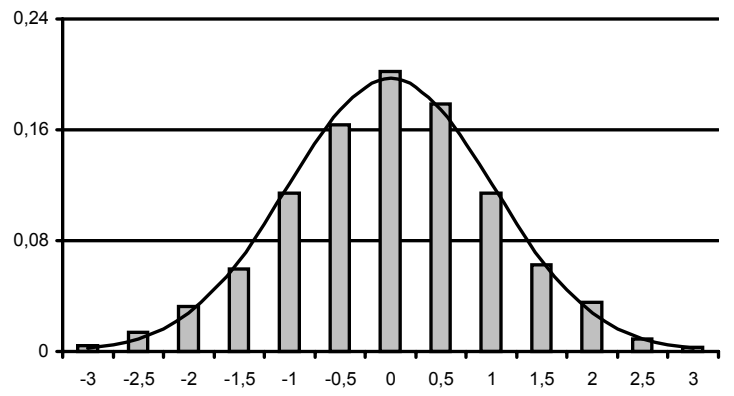

ARMA

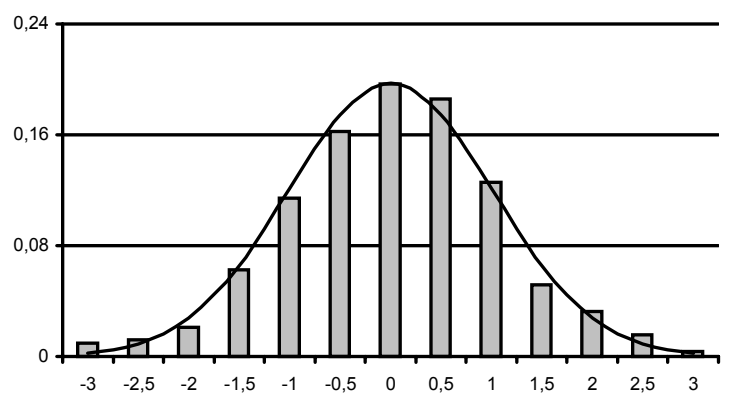


CERGE-EI

P.O.BOX 882 Politických vezòù 7

11121 Prague 1

Czech Republic http://www.cerge-ei.cz 